\title{
Rice Bran Metabolome Contains Amino Acids, Vitamins \& Cofactors, and Phytochemicals with Medicinal and Nutritional Properties
}

\author{
Iman Zarei ${ }^{1,2}$, Dustin G. Brown ${ }^{1}$, Nora Jean Nealon ${ }^{1}$ and Elizabeth P. Ryan ${ }^{1 *}$ (D)
}

\begin{abstract}
Background: Rice bran is a functional food that has shown protection against major chronic diseases (e.g. obesity, diabetes, cardiovascular disease and cancer) in animals and humans, and these health effects have been associated with the presence of bioactive phytochemicals. Food metabolomics uses multiple chromatography and mass spectrometry platforms to detect and identify a diverse range of small molecules with high sensitivity and precision, and has not been completed for rice bran.

Results: This study utilized global, non-targeted metabolomics to identify small molecules in rice bran, and conducted a comprehensive search of peer-reviewed literature to determine bioactive compounds. Three U.S. rice varieties (Calrose, Dixiebelle, and Neptune), that have been used for human dietary intervention trials, were assessed herein for bioactive compounds that have disease control and prevention properties. The profiling of rice bran by ultra-performance liquid chromatography-tandem mass spectrometry (UPLC-MS/MS) and gas chromatography-mass spectrometry (GC-MS) identified 453 distinct phytochemicals, 209 of which were classified as amino acids, cofactors \& vitamins, and secondary metabolites, and were further assessed for bioactivity. A scientific literature search revealed 65 compounds with health properties, 16 of which had not been previously identified in rice bran. This suite of amino acids, cofactors \& vitamins, and secondary metabolites comprised $46 \%$ of the identified rice bran metabolome, which substantially enhanced our knowledge of health-promoting rice bran compounds provided during dietary supplementation.
\end{abstract}

Conclusion: Rice bran metabolite profiling revealed a suite of biochemical molecules that can be further investigated and exploited for multiple nutritional therapies and medical food applications. These bioactive compounds may also be biomarkers of dietary rice bran intake. The medicinal compounds associated with rice bran can function as a network across metabolic pathways and this metabolite network may occur via additive and synergistic effects between compounds in the food matrix.

Keywords: Rice bran, Functional food, Metabolomics, Medicinal properties, Chronic diseases, Phytochemicals, Infectious diseases

\footnotetext{
* Correspondence: E.P.Ryan@colostate.edu

${ }^{1}$ Department of Environmental \& Radiological Health Sciences, College of Veterinary Medicine and Biological Sciences, Colorado State University, 1680 Campus Delivery, Fort Collins, CO 80523, USA

Full list of author information is available at the end of the article
} 


\section{Background}

Rice (Oryza sativa L.) is an essential staple food for more than half of the world's population ( $\mathrm{Hu}$ et al. 2014; Qian et al. 2016) and is grown in more than 100 countries worldwide (Muthayya et al. 2014). Rice bran, the outer covering of the rice grain, contains a unique profile of phytochemicals with medicinal and nutritional properties that are beneficial to human health, some of which have been targeted for nutraceutical development for cancer (Henderson et al. 2012; Verschoyle et al. 2007), type 2 diabetes (Cheng et al. 2010; de Munter et al. 2007; Qureshi et al. 2002), lipid metabolism regulation (Kuriyan et al. 2005; Qureshi et al. 1997; Shibata et al. 2016; Wang et al. 2015), immune regulatory processes (Wang et al. 2015), and obesity (Ham et al. 2015). Furthermore, we recently showed whole rice bran can protect against enteric pathogens such as Salmonella enterica serovar Typhimurium, human rotavirus, and human norovirus (Goodyear et al. 2015; Kumar et al. 2012; Lei et al. 2016; Yang et al. 2015). Rice bran contains nonsaponifiable lipids (i.e. gamma oryzanol), vitamin E (e.g. tocopherols and tocotriols), polyphenols (e.g. ferulic acid caffeic acid and salicylic acid), and phytosterols (e.g. betasitosterol) (Henderson et al. 2012) with reported health properties. Many of these compounds are available in the lipid fraction and also known as rice bran oil (Charoonratana et al. 2015; Iqbal et al. 2003; V. Panala, 2009). Additional compounds from other chemical classes in rice bran merit attention and can be identified via high throughput techniques, such as global, nontargeted metabolomics that can assess a large profile of small molecules present in the whole food. Given the emphasis in previous studies on rice bran lipids (Forster et al. 2013), this analysis focused on rice bran amino acids, cofactors \& vitamins, and secondary metabolites that have medicinal and nutritional properties important to human health.

Despite the large body of scientific evidence on rice bran bioactivity, rice bran remains underutilized in human health and nutrition because it is considered an animal feed and is known to undergo hydrolytic rancidity after processing from whole grain rice (da Silva et al. 2006; Ramezanzadeh et al. 1999a, b). Thermal treatments applied to rice bran have helped to stabilize it and prevents rancidity by the inactivation of lipases and peroxidases. One major obstacle to achieving widespread human consumption and acceptance of rice bran is the global perception that rice bran is an animal feed (Ramezanzadeh et al. 1999a).

Food metabolomics, or "Foodomics", provides information on the presence and relative abundance of all compounds in a food matrix. Food metabolome studies have shown compounds across diverse chemical classes such as amino acids, lipids, sugars, peptides, organic acids, phenolic compounds and other secondary metabolites (Wishart, 2008). Entire metabolite profiles have been completed on several foods including cooked and uncooked rice grain (Heuberger et al. 2010; Hu et al. 2014; Kim et al. 2013a, 2013b), grape (Vitis vinifera L.) (Luca Narduzzi, 2015), human milk (Andreas et al. 2015; Wu et al. 2016), tomato (Moco et al. 2006), citrus juice (Arbona et al. 2015), and several other foods and crops (e.g., carrot, beer, wine, and coffee) (Johanningsmeier et al. 2016) through non-targeted screening methods. Nutritional metabolomics is an experimental approach that uses small molecule profiling to integrate the effects of diet on nutrition, and thus can be used to evaluate the health effects of foods at an individual level (Jones et al. 2012). Integrating food and nutritional metabolomic approaches can increase our knowledge on the bioactivity of food metabolites, and may increase evidence for metabolic mechanisms by which foods elicit important health effects (Capozzi and Bordoni, 2013; Herrero et al. 2012). Accurate food metabolite profiles in regards to food and nutritional metabolomics may also assist in the quantification of dietary intakes and specific food biomarkers.

The goal of the food metabolome approach applied herein was to obtain a complete characterization of the rice bran small molecule profile for bioactive components. This study used non-targeted metabolomics to investigate heat-stabilized rice bran from three U.S. rice cultivars for the identification of metabolites with medicinal and nutritional properties. These varieties were chosen for profiling based on human consumption in clinical trials, whereby rice bran intake improved intestinal health parameters by modulating gastrointestinal microbiota and host immunity (Borresen et al. 2016; Sheflin et al. 2016; Yang et al. 2015). The hypothesis was that rice bran contains a distinct stoichiometry of small molecules, covering multiple classes of phytochemicals, including but not limited to amino acids, cofactors \& vitamins, and secondary metabolites that have medicinal properties and contribute to the nutritional benefits of rice bran as a whole food. A thorough examination of metabolites across chemical classes revealed a complex network of metabolic pathways that have not been previously examined for rice bran. A detailed analysis of rice bran functional food components allowed for a thorough understanding of how a suite of metabolites in a single food can exhibit therapeutic and preventive medicine properties.

\section{Results}

Non-Targeted Rice Bran Metabolomics

The metabolite profile composition of rice bran revealed 453 metabolites with known identity that were clustered into the following metabolic pathways: amino acid 
(126 metabolites), carbohydrate (35 metabolites), cofactors \& vitamins (28 metabolites), energy (11 metabolites), lipids (137 metabolites), nucleotides (40 metabolites), peptides (28 metabolites), secondary metabolites (55 metabolites), and xenobiotics (8 metabolites). Total metabolite numbers for each metabolic pathway are shown in Additional file 1: Table S1. Approximately $46 \%$ of total identified metabolites (209 metabolites) were classified as amino acids, cofactors \& vitamins, and secondary metabolites and were interrogated for their potential human health-promoting properties. Medicinal and health promoting attributes were previously reported in the scientific literature for 65 rice bran metabolites from these three pathways. Table 1 lists the 29 amino acids, Table 2 lists the 13 cofactors \& vitamins, and Table 3 lists the 23 secondary metabolites with previously reported health beneficial properties. A total of 16 out of 65 metabolites (noted by ${ }^{1}$ in tables) with medicinal/nutritional properties were identified from this metabolome analysis that had not previously been reported from rice bran. These included 9 amino acids, 2 cofactors \& vitamins, and 6 secondary metabolites.

Amino acids constituted $\sim 28 \%$ of the rice bran metabolome from the three rice bran varieties tested. Of the 29 amino acids with medicinal properties in Table 1, 13 had reported antioxidant and/or anti-inflammatory activities, 6 compounds with known antimicrobial properties, 5 that were anti-hypertensive, 4 metabolites with lipid-lowering effects, 3 with cancer chemopreventive actions, one with evidence for prevention of obesity, and one metabolite with hypoglycemic, antidiabetic properties. Multiple metabolites, including taurine and betaine, varied in relative abundance across U.S. varieties, and exhibited more than one mechanism of action with nutritional benefits.

Figure 1 is a Cytoscape pathway classification network view specific to amino acids present in Calrose rice bran. The metabolite taurine is presented by a closed black node extending from methionine, cysteine, S-adenosylmethionine (SAM), \& taurine pathway node, which connects to the central, hexagonal amino acid network node. Node size indicates the relative abundance Z-score for the metabolite. The median-scaled relative abundance for each metabolite in Table 1 can be inferred by the size of the node. For example, taurine (methionine, cysteine, S-adenosyl- methionine (SAM), \& taurine pathway) has a bigger node size (i.e., bigger Z-score) when compared with betaine (glycine, serine and threonine metabolic pathway).

Cofactors and vitamins constituted $\sim 6 \%$ of the rice bran metabolome. The 13 metabolites with established medicinal properties are listed in Table 2, with novel identifications of glucarate (median-scaled relative abundance of $0.89,0.13$ for Calrose and Dixiebelle respectively, and non-detectable in Neptune), and threonic acid (median-scaled relative abundance of 36.15, 20.99, and 16.44 for Calrose, Dixiebelle, and Neptune respectively) from rice bran. We found 6 cofactors \& vitamins that had antioxidant and/or anti-inflammatory properties, 5 compounds had anti-hypertensive activity, 2 compounds had shown lipid-lowering effects, 4 compounds had evidence for cancer chemopreventive action, and one metabolite was a hypoglycemic agent and antidiabetic.

Figure 2 shows the Cytoscape pathway classification node network view for cofactors \& vitamins metabolic pathways. The micronutrient richness of rice bran is depicted by inclusion of vitamin B6, ascorbate \& aldarate, and nicotinate \& nicotinamide sub-metabolic pathways with metabolite examples of pyridoxine, threonic acid, and nicotinate for each metabolic pathway, respectively.

The plant secondary metabolites from rice bran constitute more than $12 \%$ of the metabolome. From the 23 rice bran phytochemicals in Table 3 that have known medicinal properties, we identified 16 phytochemicals with antioxidant and/or anti-inflammatory properties, 9 that had antimicrobial effects, 2 components that were anti-hypertensive, 1 with lipid-lowering effects, 4 compounds with evidence of cancer chemoprevention, 1 had scientific reports for utility in obesity prevention, and 4 phytochemicals demonstrated hypoglycemic and antidiabetic properties. Figure 3 shows all of the secondary metabolites from the rice bran metabolome across three U.S. varieties with respect to their median-scaled relative abundances. Ferulate is an example of a secondary metabolite that has a relative abundance of 6.22 , 10.28, and 19.69 in Calrose, Dixiebelle, and Neptune, respectively. Levels of this metabolite are in contrast to tartaric acid, which was $0.31,0.32$, and 0.26 . The varied relative abundance detected across metabolites from diverse pathways supports the utility of a metabolome approach.

Figure 4 is the Cytoscape network view of the 16 newly identified metabolites within these metabolic pathways for Calrose (i.e. amino acids, cofactors \& vitamins, and secondary metabolites) and their respective sub-metabolic pathways.

\section{Calrose, Dixiebelle and Neptune have Similar Bran Metabolomes}

To assess the potential for differences in the relative abundances of small molecules in Calrose, Dixiebelle, and Neptune, we performed a principal component analysis (PCA). Principal component 1 revealed 54\% variance among these three rice bran cultivars (Fig. 5), yet this percent variation using PCA did not reach statistical significance, and a lower level of variation is expected between these three U.S varieties when compared to a 


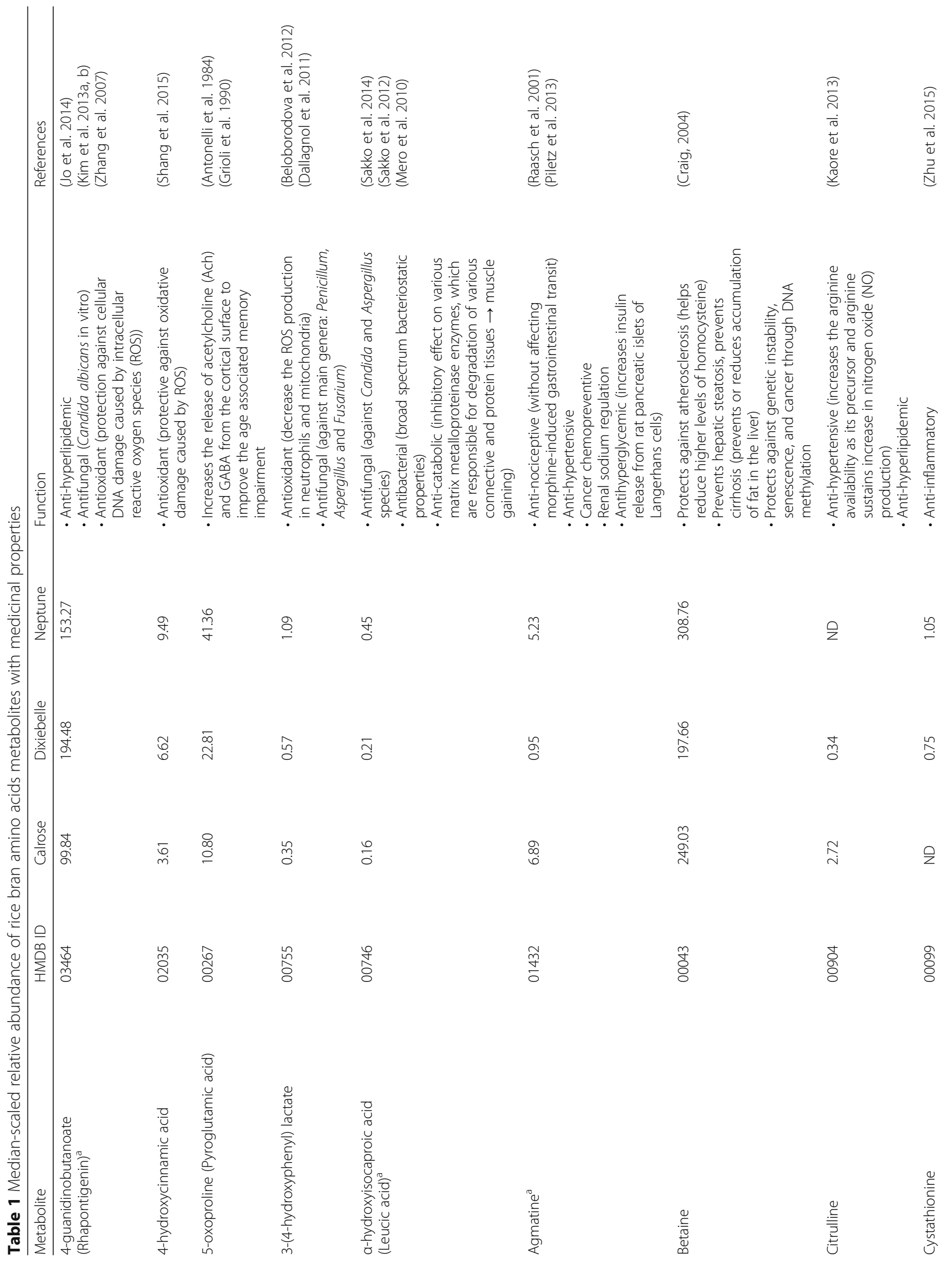




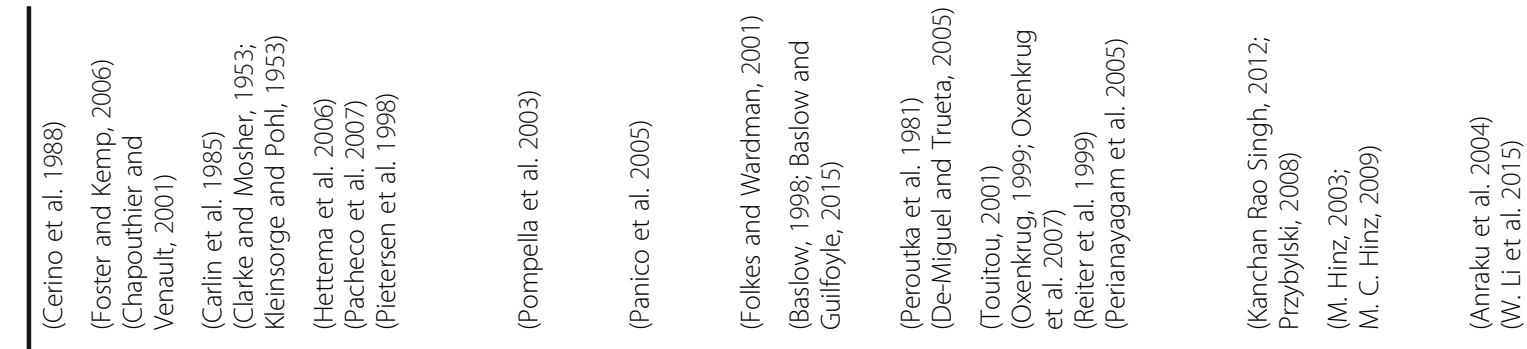

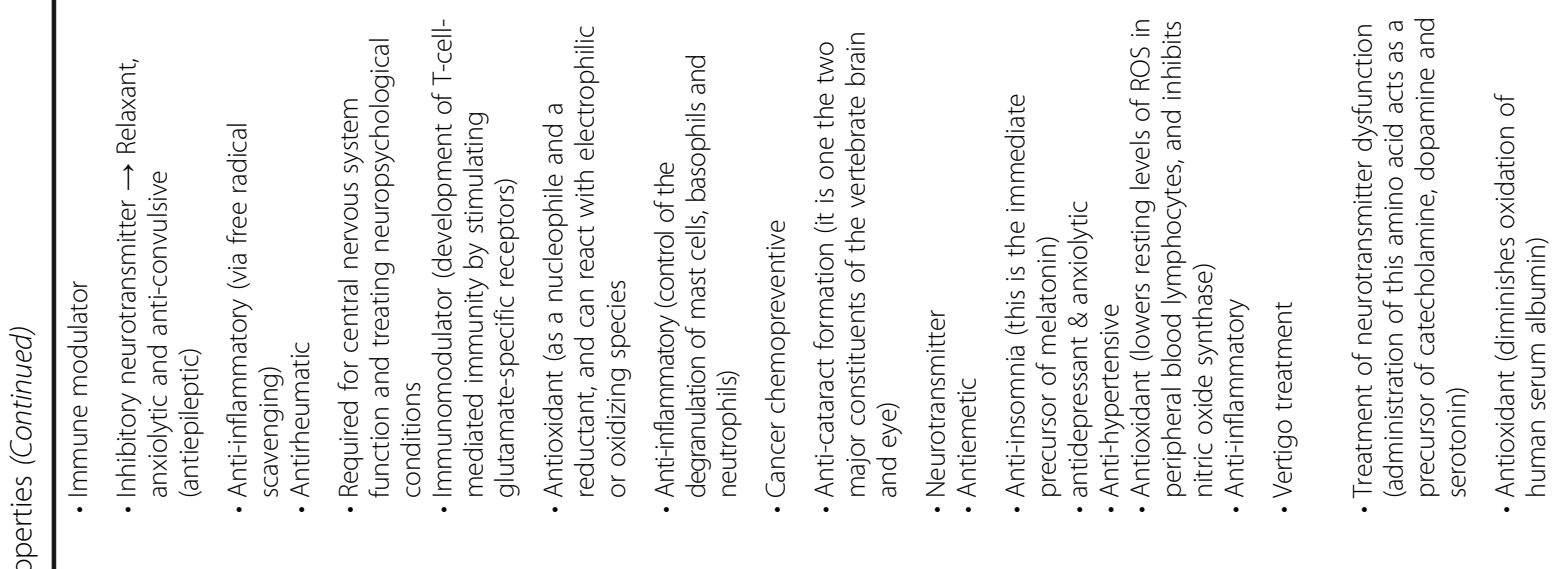

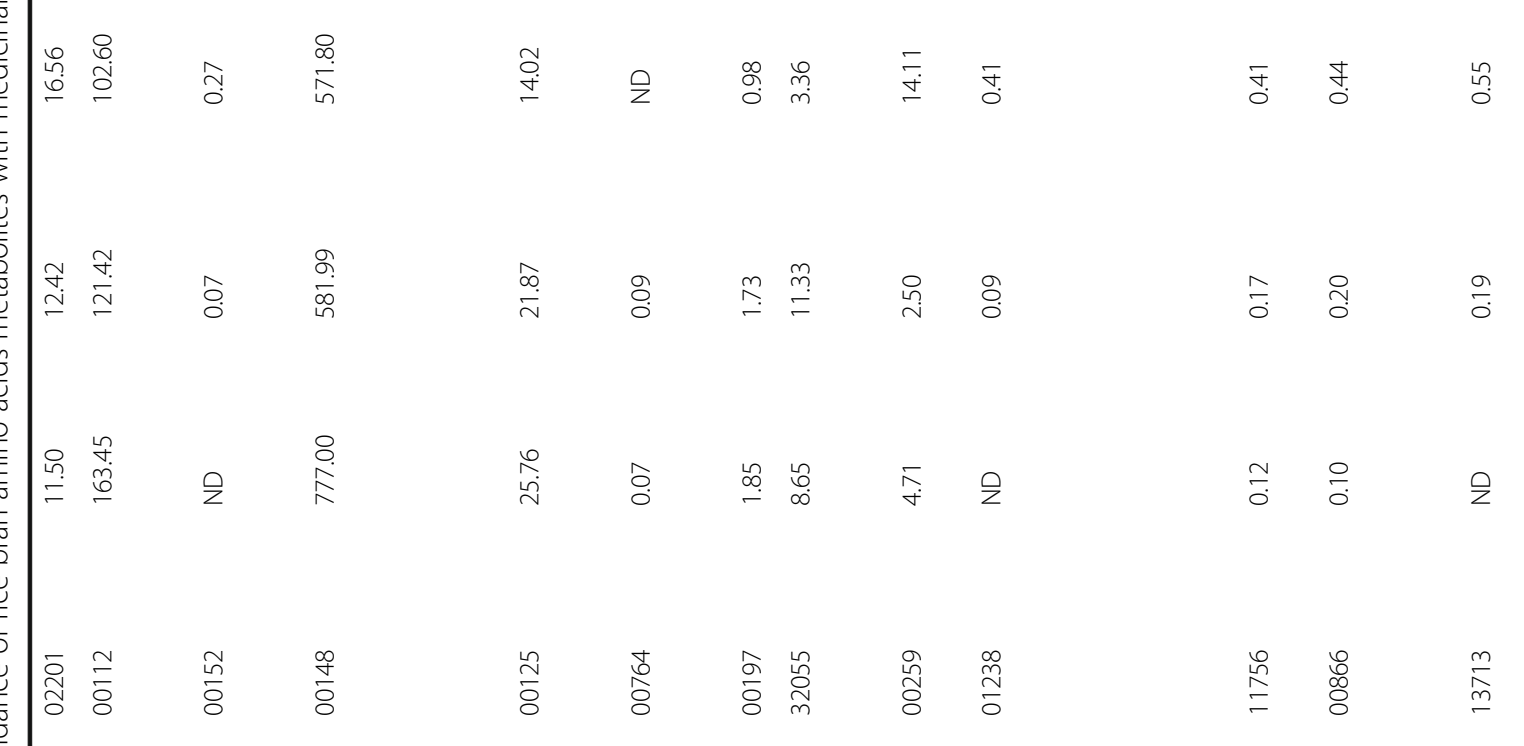



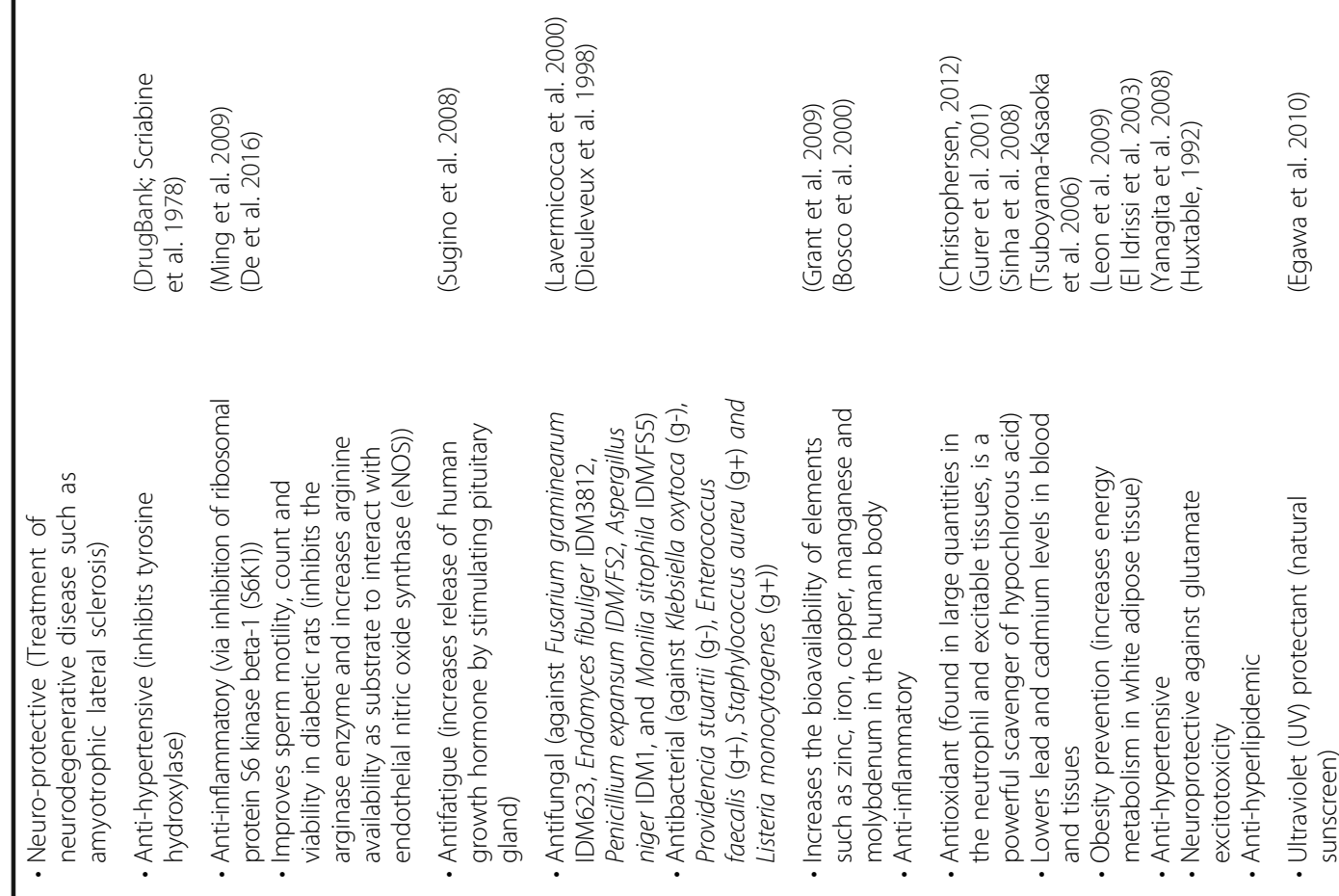

₹

กิ่ กิ่

$\frac{\sigma}{\circ} \quad \frac{\sigma}{\sigma}$

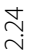

之

$\stackrel{ }{\stackrel{n}{\circ}}$

$\stackrel{\circ}{\circ}$

$\hat{\delta}$

$\stackrel{m}{\circ}$

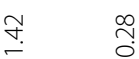

กิ

$\stackrel{\infty}{\circ}$

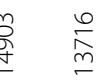

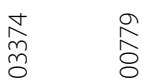

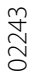

๘ัฒ

ळ.

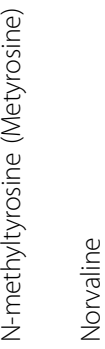

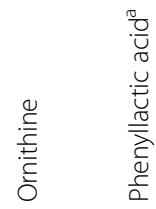

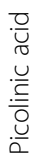

胥

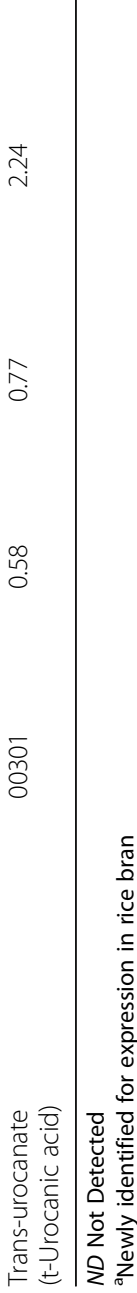




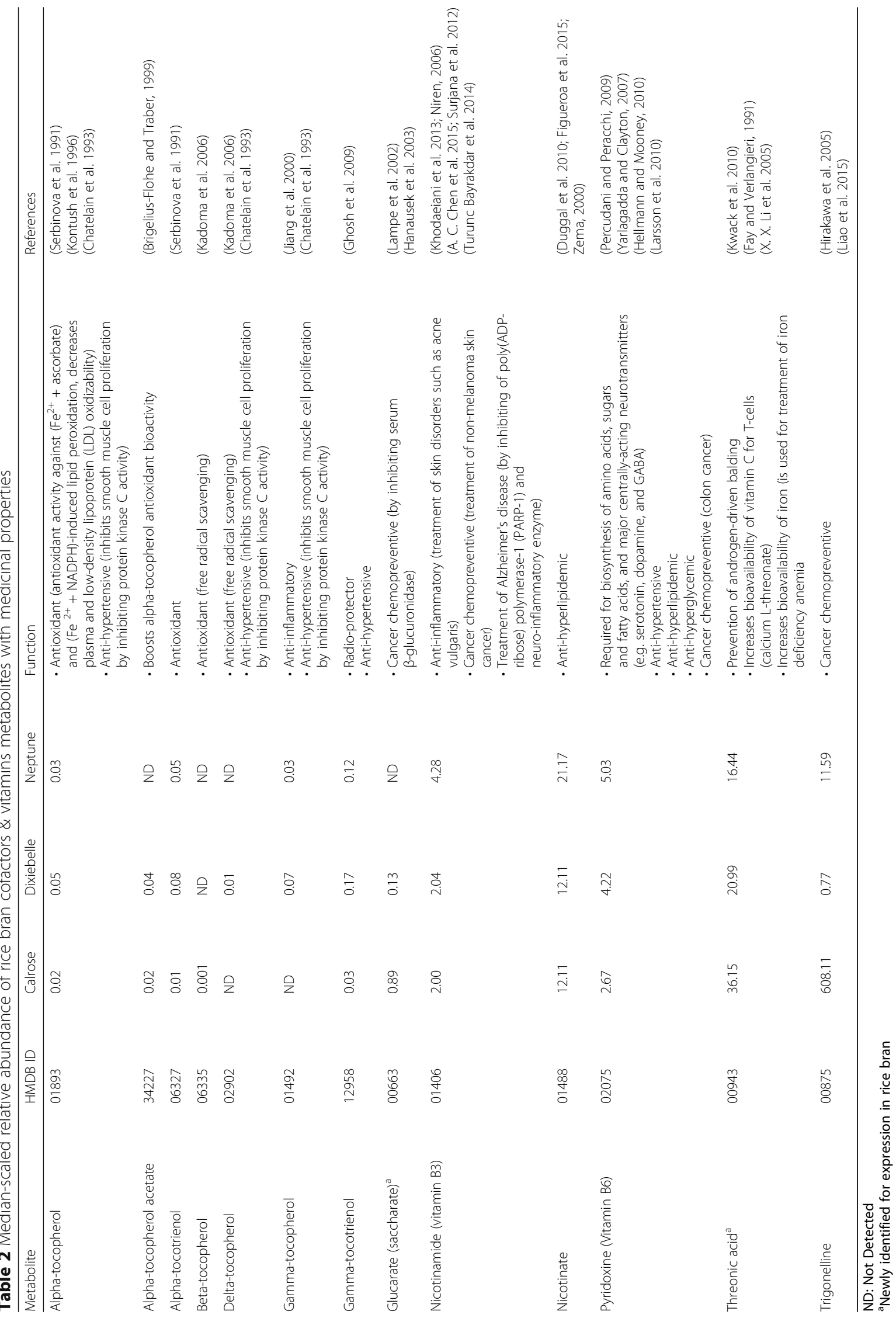




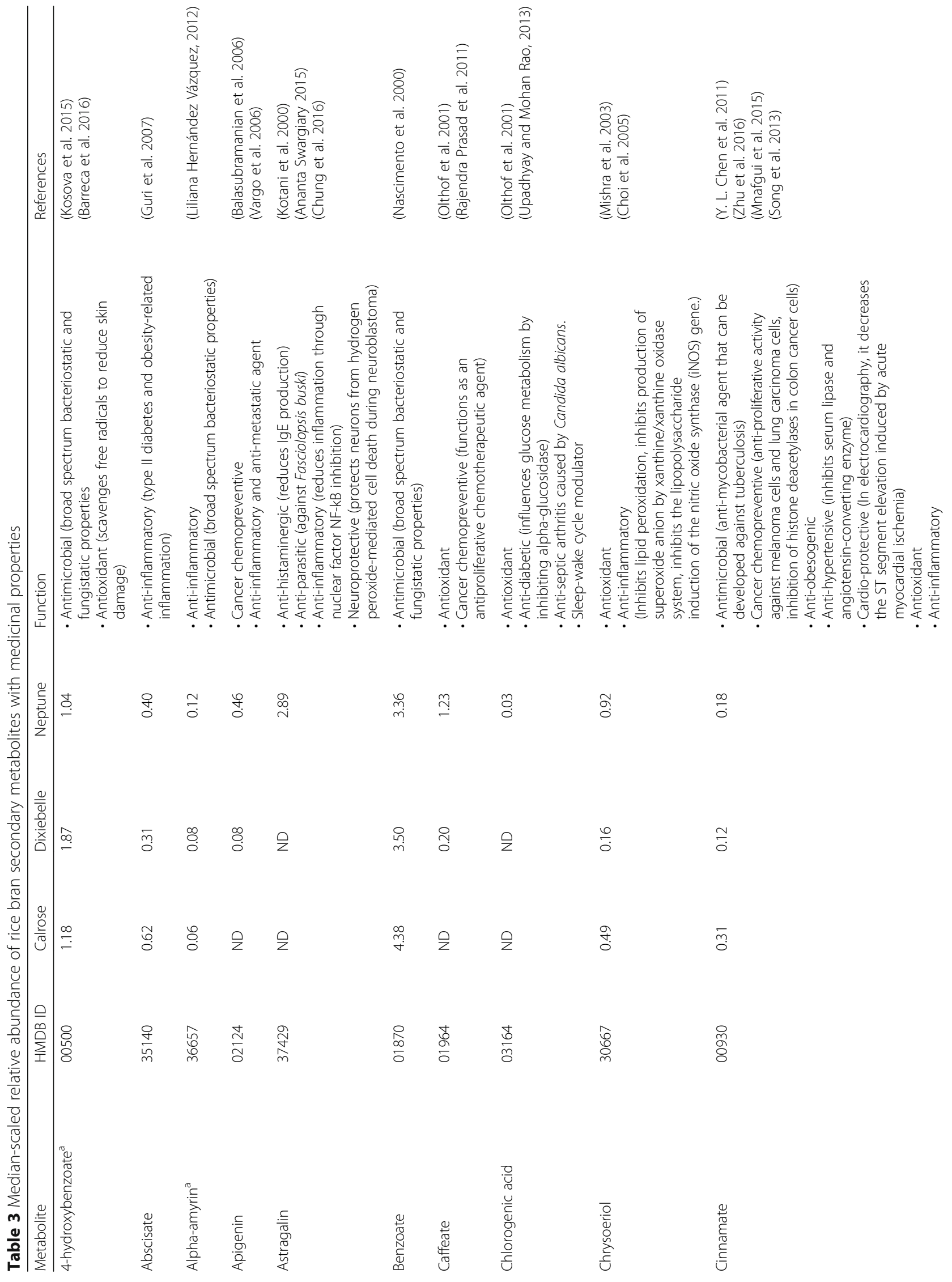




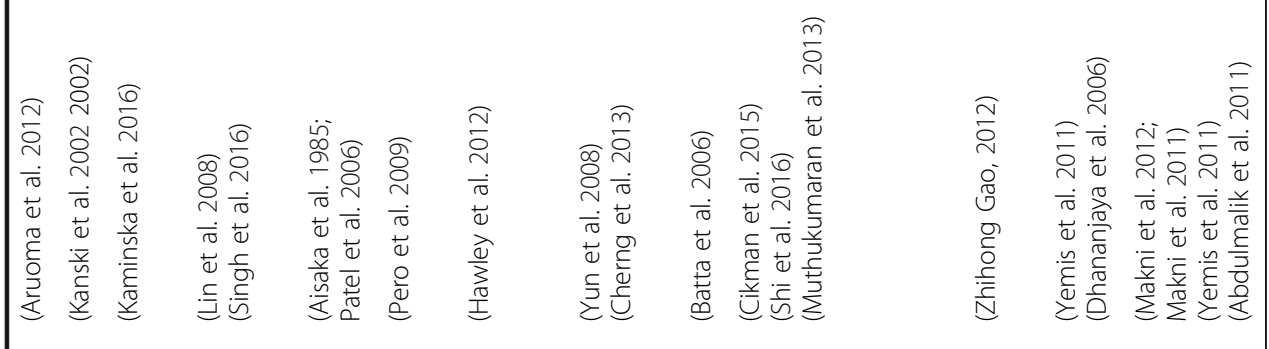

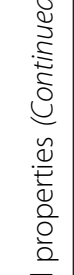
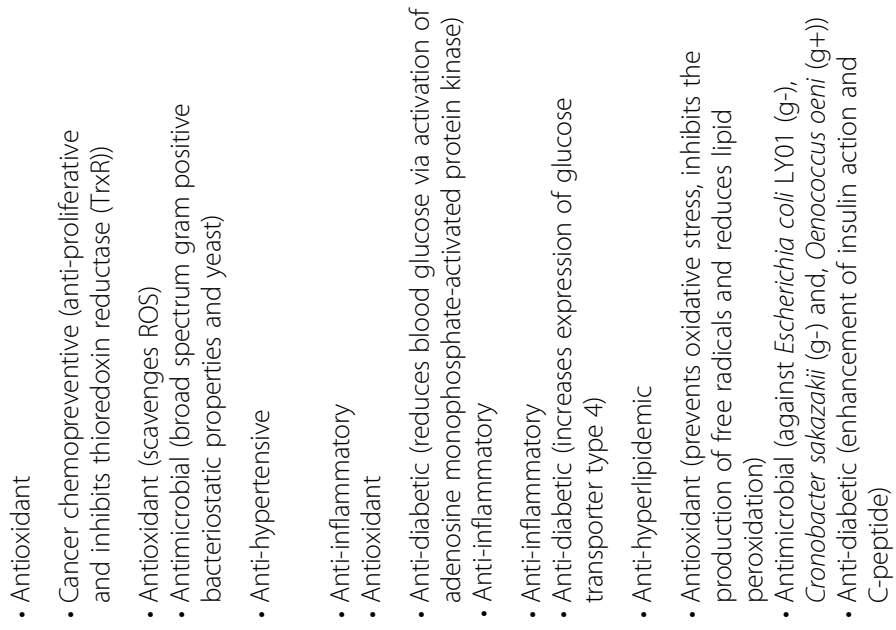

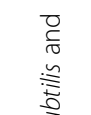

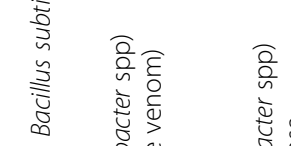

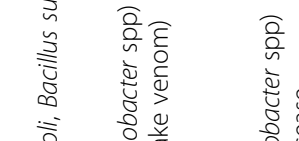

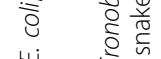

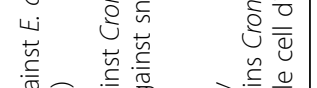

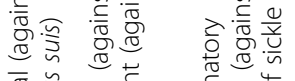

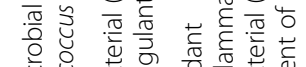

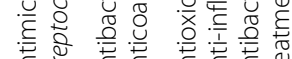

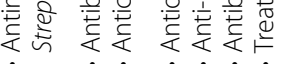

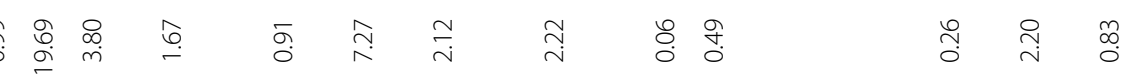

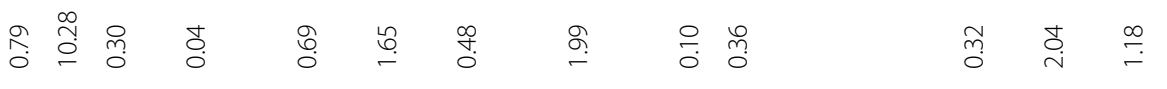

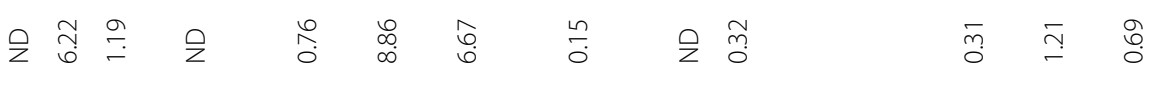

0
$\frac{0}{0}$
$\frac{\pi}{0}$
$\frac{0}{5}$
$\frac{0}{0}$
0
0
0

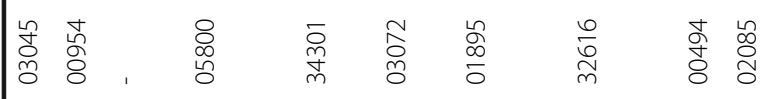

岕

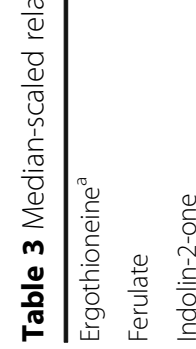

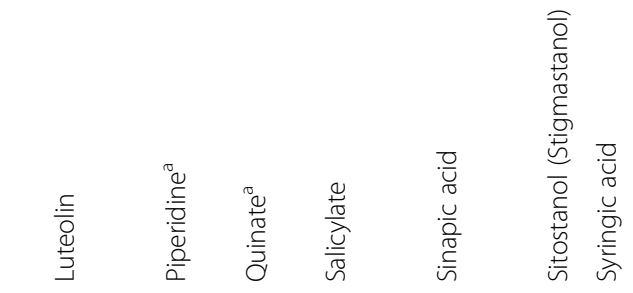

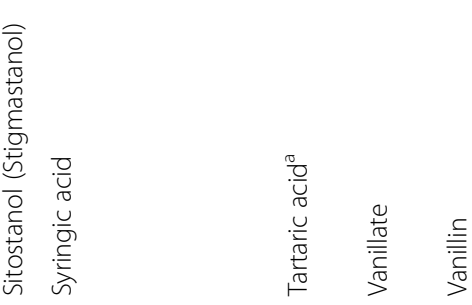




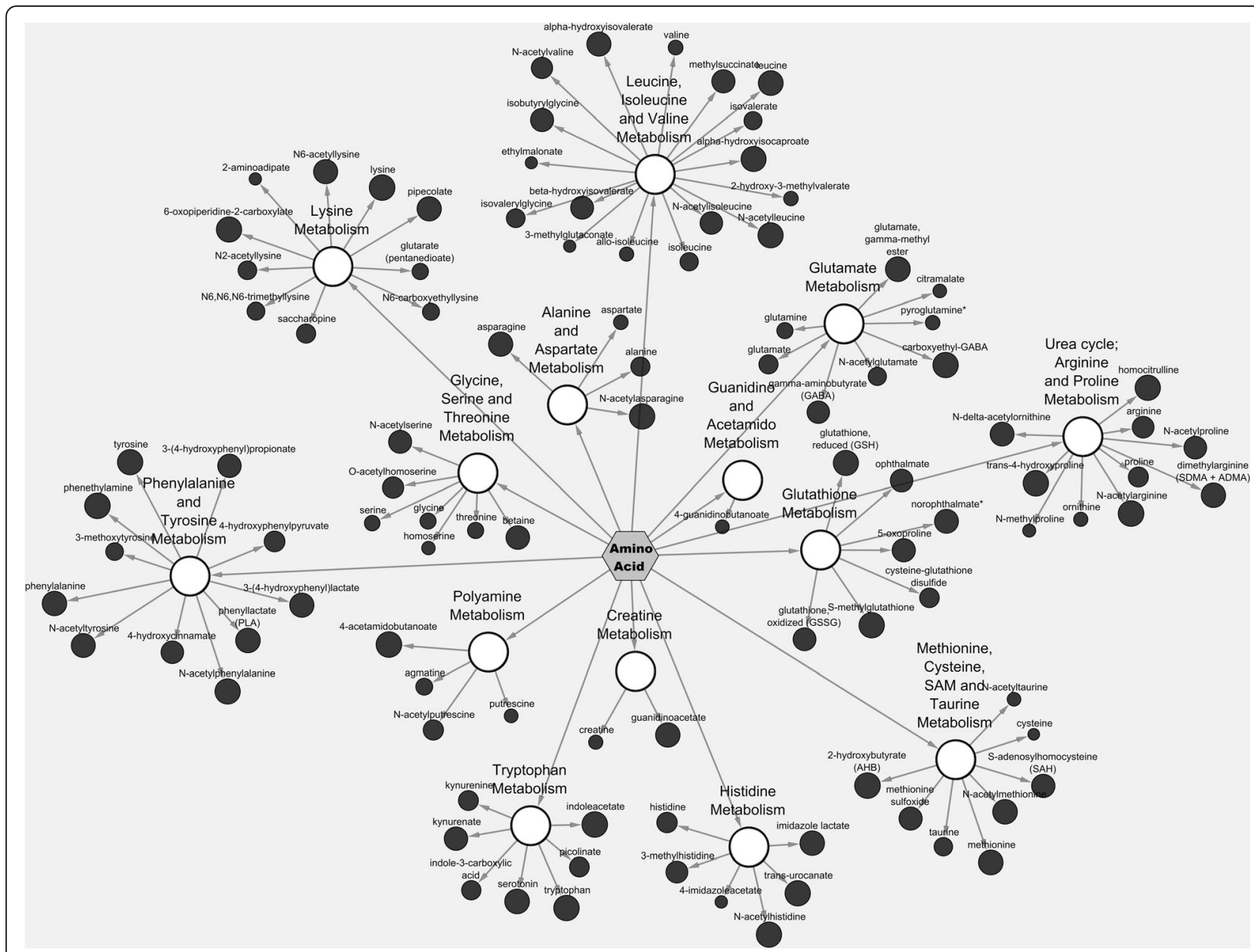

Fig. 1 Cytoscape network analysis of rice bran amino acid metabolic pathways. Pathway specific network visualization is shown for Calrose rice bran. Each metabolite is represented as a node (circle), extending from a central sub-metabolic pathway node. The central hexagon represents the super metabolic pathway. Node size corresponds to the Z-score using the relative abundance mean value for all three varieties

larger sample set of global varieties with established genome diversity.

\section{Discussion}

The rice bran metabolome analysis herein focused on amino acid, cofactor \& vitamin, and secondary metabolite compounds that exhibited medicinal and nutritional properties with an emphasis on chronic and infectious disease control and prevention. The three selected classes of metabolites represented $\sim 46 \%$ of total rice bran metabolite profile. Metabolites were described as antioxidative and anti-inflammatory (35 metabolites), antimicrobial (15 metabolites), anti-hypertensive (12 metabolites), cancer chemopreventive (11 compounds). anti-hyperlipidemic (8 metabolites), anti-hyperglycemic (6 compounds), and anti-obesogenic (2 compounds).

Antioxidants represented a broad class of compounds available from many different foodstuffs (Carlsen et al. 2010). Rice bran is a promising candidate for dietary supplementation and nutritional therapy for prevention of chronic and infectious disease via its antioxidant composition. A majority of the rice bran antioxidants (e.g. 4-guanidinobutanoate and taurine from amino acids, tocopherols and tocotrienols from cofactors \& vitamins, and ergothioneine and quinate from secondarymetabolites) work through different mechanisms to combat lipid peroxidation, DNA damage, protein modification, and enzyme inactivation caused by free radicals, in particular reactive oxygen species (ROS) (Lü et al. 2010; Nimse and Pal, 2015). Oxidative stress caused by free radicals damages host cells and may initiate early stage development of chronic diseases such as cancer, heart disease, Alzheimer's disease, arthritis, cataracts, diabetes, and kidney disease (Morales-González, 2013). Antioxidants from rice bran can safely interact with and detoxify free radicals to stop the chain of damaging reactions for disease prevention (Iqbal et al. 2005; Jun et al. 2012; Parrado et al. 2006; Parrado et al. 2003). For 


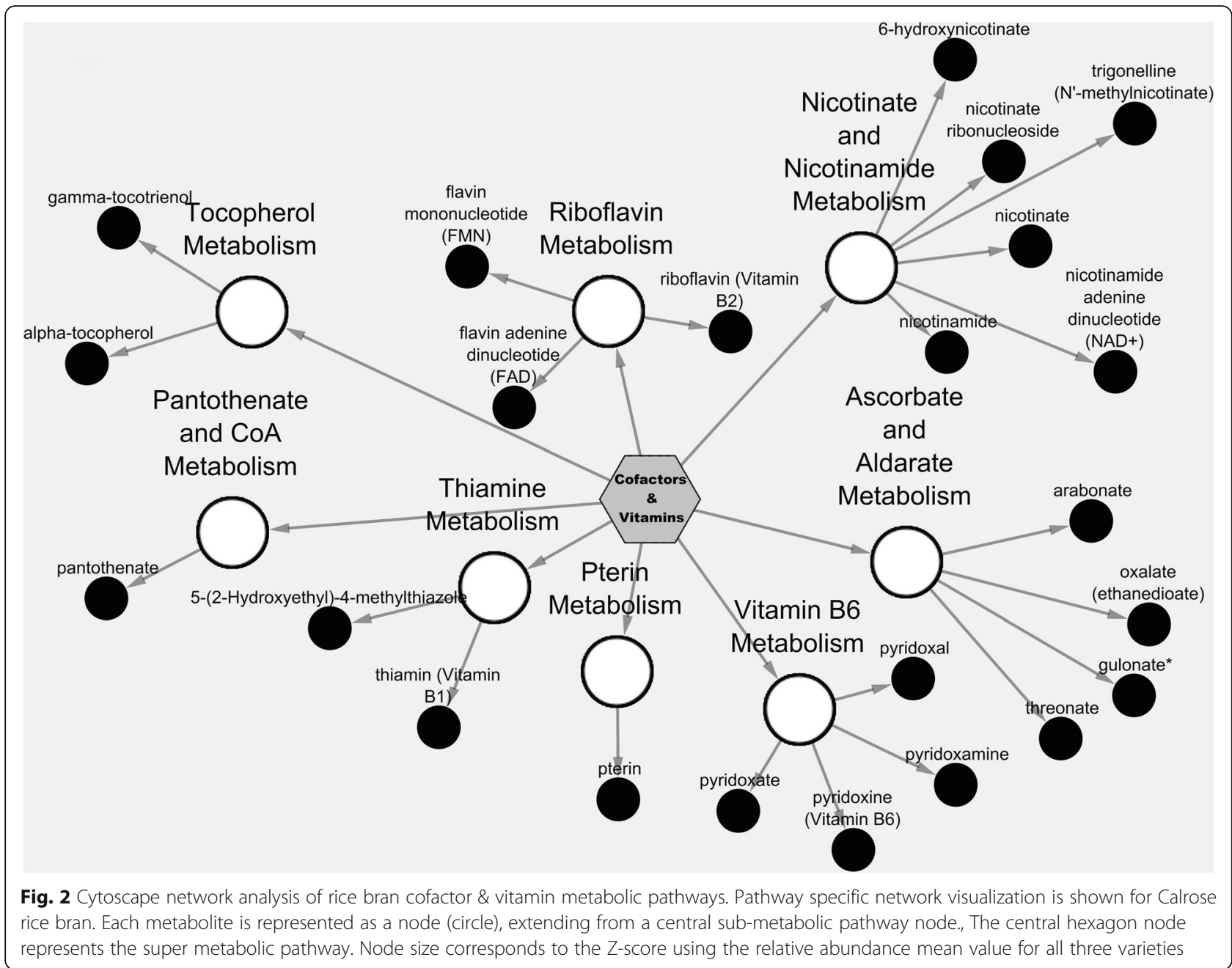

example, quinate, an antioxidant that is naturally synthesized in plants and microorganisms is now described from rice bran via metabolomics (Fig. 4). It was shown that consumption of 3000 milligrams of quinic acid ammonium chelate per day can regulate activation of NF$\mathrm{kB}$ (nuclear factor kappa-light-chain-enhancer of activated $B$ cells) and enhances DNA repair by increasing serum thiol levels (Pero et al. 2009). Rice bran derived quinate merits further evaluation for similar antioxidant activities.

The antimicrobial activity of dietary rice bran can be attributed to at least 15 metabolites across amino acids and secondary metabolites. Understanding the relative contribution of rice bran compounds and the mechanisms of antimicrobial action could be helpful in combating emerging and existing problems associated with resistance to antibiotics. Hence, treatment strategies using natural food molecules from rice bran may prevent progression of infection and associated symptoms as a sustainable, globally available long-term solution (Cowan, 1999; Kondo et al. 2011; Srivastava et al. 2014).
For instance, luteolin is a rice bran flavonoid (shown in Table 3) that reduced the growth of a variety of grampositive bacteria and yeast (Singh et al. 2016; Srivastava et al. 2014). We, and others, have previously shown that dietary rice bran has antimicrobial activity in animals and on isolated bacterial strains (Goodyear et al. 2015; Irfan A Ghazi et al. 2016; Kim et al. 2014; Kondo et al. 2011; Kumar et al. 2012; Nealon et al. 2017; Yang et al. 2015; Yang et al. 2014). Our study revealed two newly identified rice bran amino acids (out of 15) and three newly identified rice bran secondary metabolites with antimicrobial properties; Phenyllactic acid and $\alpha$-hydroxyisocaproic acid (leucic acid) from the amino acid metabolic pathway, and 4hydroxybenzoate, alpha-amyrin, and tartaric acid from the secondary metabolite metabolic pathway. Phenyllactic acid is found in many bacteria as a metabolic byproduct (e.g. Lactobacillus spp.) but not previously identified in any plant sources (Valerio et al. 2004). Leucic acid has been identified in fermented foods, including certain cheeses, wines, and soy sauce (Mero et al. 2010). 4hydroxybenzoate has been previously found in pistachio 

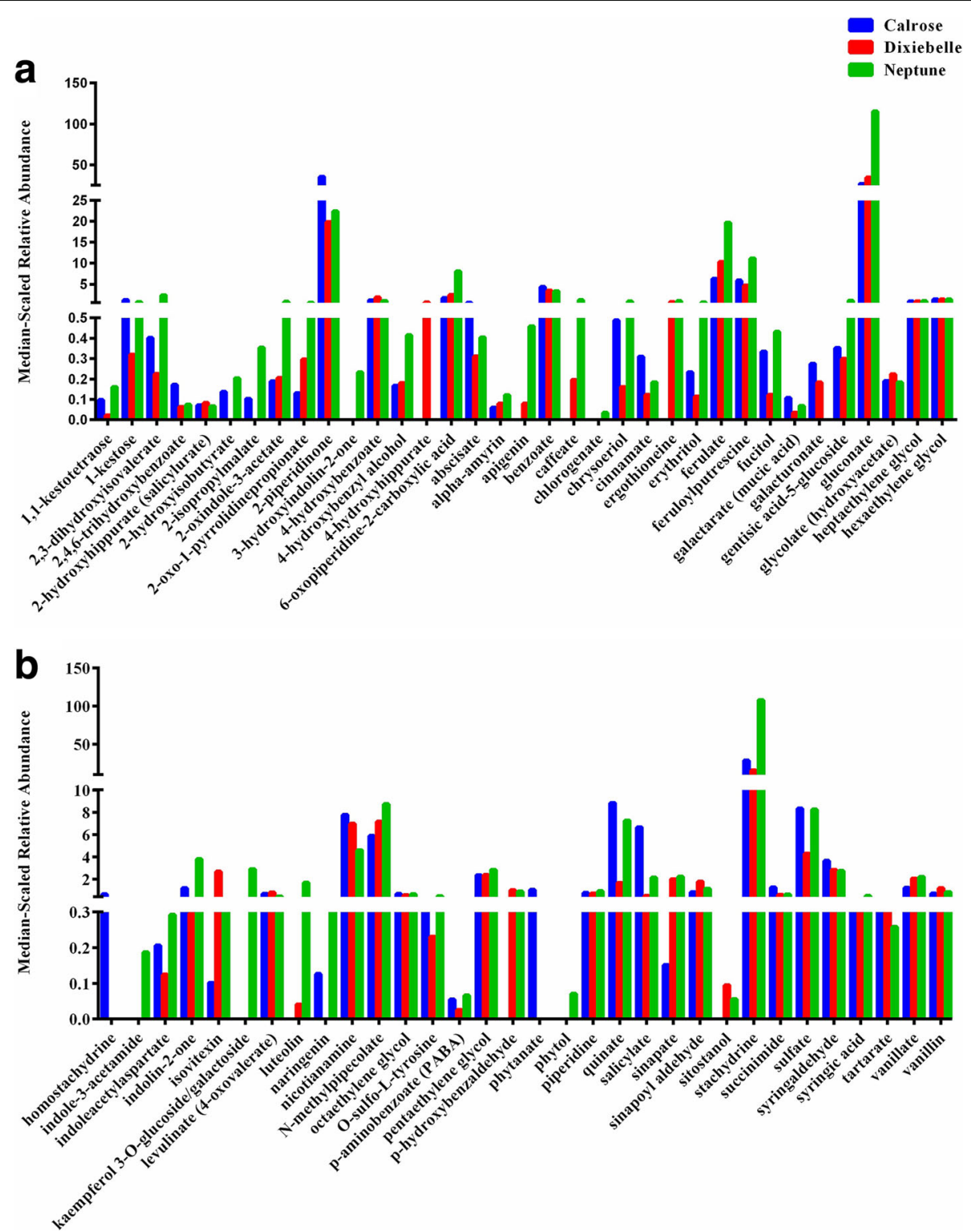

Fig. 3 Secondary metabolites detected in rice bran across 3 U.S. varieties. Rice bran metabolites were normalized by median of relative abundance for the entire dataset. a shows half of metabolites identified within secondary metabolites metabolic pathways and their difference in median-scaled relative abundance across three varieties. $\mathbf{b}$ shows another half of identified secondary metabolites and their difference in medin-scaled relative abundance across three varieties

hulls (Barreca et al. 2016). Alpha-amyrin is found in Carissa carandas (karanda fruit) (Akansha Singh, 2015). Additionally, tartaric acid has been found in Hibiscus sabdariffa flower (Da-Costa-Rocha et al. 2014). Our metabolomics analysis results suggest that nutritional therapy through rice bran's multi-faceted antimicrobial actions merits testing in medical clinical applications to mitigate microbial resistance.

Rice bran merits attention for being of considerably high nutritional value. These metabolome analyses confirm that it is a rich source of proteins, fats, minerals and micronutrients, such as B vitamins and trace elements. For example, at $12-15 \%$ protein content and with protein digestibility that is comparable to casein, the macro-nutritional value of rice bran which also contains healthy fats and fibers warrants greater pubic health attention (Saunders, 1990; Wang et al. 1999). Rice bran is also a rich source of B-complex vitamins, particularly thiamine and nicotinic acid, riboflavin and vitamin $B_{6}$. A single serving of rice bran (28 grams in accordance to USDA) delivers more than half of the daily nutritional requirements for thiamine, niacin and 


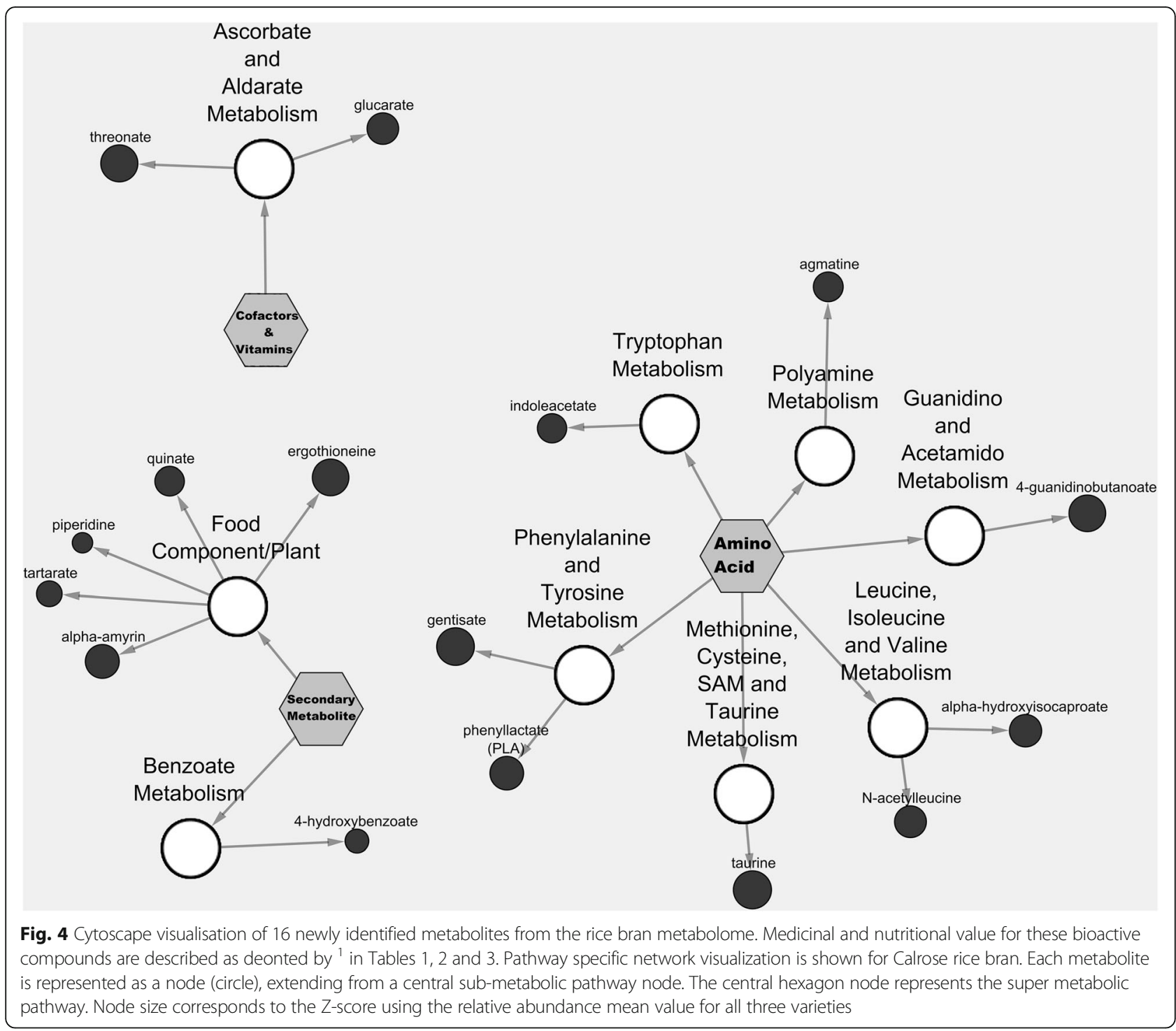

vitamin B6 (based on a 2,000 calorie reference diet) (SELFNutritionDada; United States Department of Agriculture, 2016). Vitamins cannot be synthesized by the body and must be ingested, as such inadequate intake or subtle deficiencies in vitamins are risk factors for multiple chronic diseases (Fairfield and Fletcher, 2002). Recent evidence showed intake levels of thiamin, niacin, vitamin $B_{6}$, total folate, and alpha-tocopherol was improved in colorectal cancer survivors consuming rice bran and suggests that foods with multiple bioactive components and nutrients can play a pivotal role in the prevention of chronic diseases such as cancer and cardiovascular disease (Borresen et al. 2016; Borresen EC, 2016).

A major strength of the non-targeted metabolomics approach herein was the identification of novel compounds from rice bran with medicinal properties (Fig. 4). The limitations of non-targeted metabolomics in dietary exposure biomarker discovery platforms arise from metabolite concentrations that can vary across cultivars, and inconsistencies in extraction methods or instrument detection limits. Additional limitations for results interpretations from this study involve the limited information for bioavailability of rice bran compounds. The biological properties for rice bran will be dependent on host bioavailability and bioaccessiblity following ingestion, and thus this rice bran food metabolome investigation will assist to identify rice bran exposure biomarkers of intake in people. The variation in gut microbiota composition is another major factor that can influence bioavailability of food metabolites as well as the biological activities (Conlon and Bird, 2015; Krajmalnik-Brown et al. 2012). This is the first nontargeted whole food metabolome study of rice bran with an investigative focus towards the suites of amino acids, cofactors \& vitamins, and secondary metabolites. 


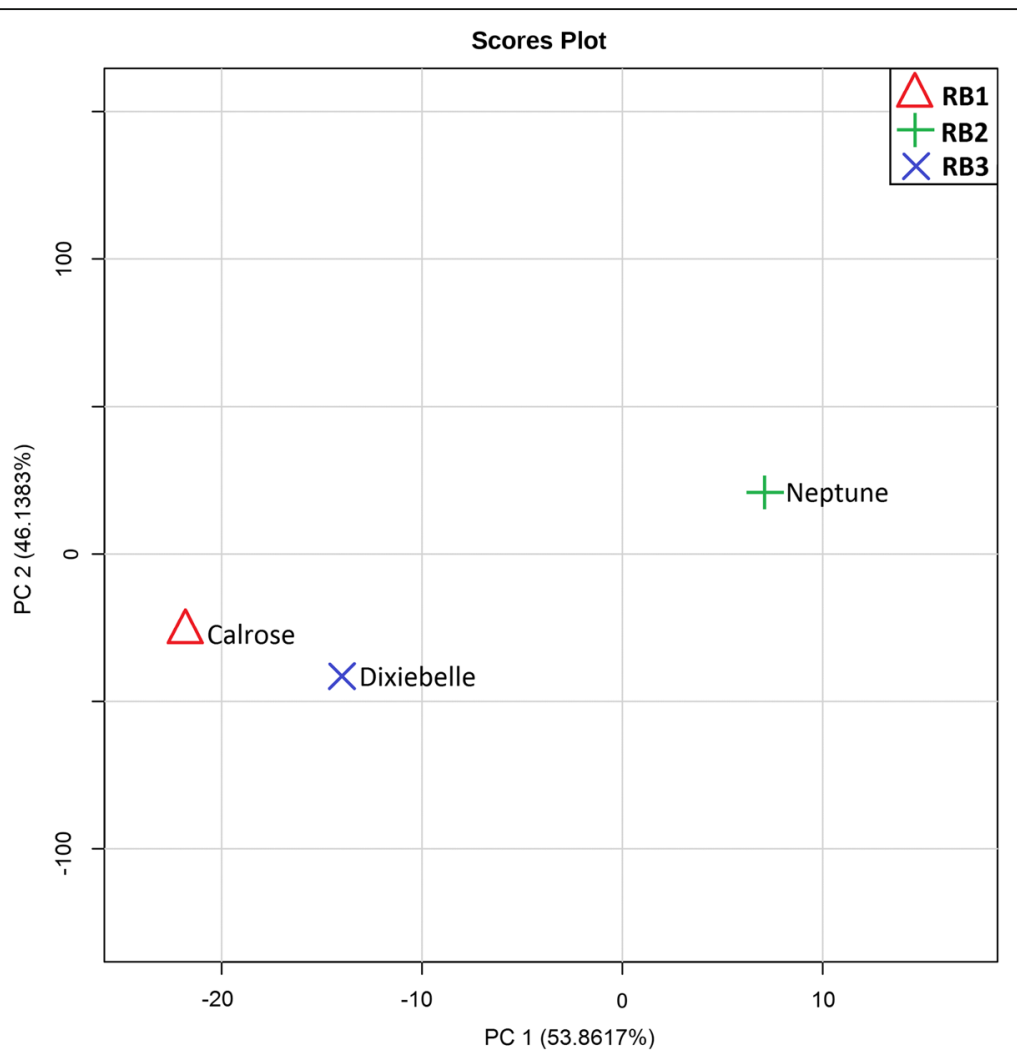

Fig. 5 Principal Component Analysis of three U.S. varieties. Principal component analysis (PCA) revealed that the first component described 54\% variation herein and between separation of Calrose, Dixiebelle and Neptune rice bran cultivars. The second component describing $46 \%$ of the variance did not separate the varieties. No statistical significance was established between the metabolites detected from each of the three U.S rice varieties analyzed

Additional metabolic pathways and chemical classes of metabolites from this analysis (listed in Additional file 1: Table S1) merit continued investigation for medicinal properties and nutritional value.

\section{Conclusions}

This study identified approximately 453 metabolites from the rice bran metabolome, many of which are described herein as cofactors \& vitamins, amino acids and secondary metabolites. These metabolic pathways, among others found in rice bran, have shown positive health effects in animals and humans. The wide range of phytochemicals found in rice bran are likely working synergystically to contribute to rice bran's functional food properties. The ability of rice bran to fight both infectious and chronic diseases may be in part due to synergistic combinations of phytochemicals, and alongside metabolism by the gut microbiota (Borresen et al. 2016; Sheflin et al. 2016; Sheflin et al. 2015). Rice bran biochemical composition merits further investigation for multiple nutritional therapies and medical food applications.

\section{Methods}

Rice: Milling and Heat Stabilization of Bran

Rice bran from 3 U.S. rice varieties (Calrose, Dixiebelle, and Neptune), representive of rice production in the southeastern U.S. and California, were chosen for this study (Additional file 2: Table S2). Bran was collected and heat stabilized by the United States Department of Agriculture-Agricultural Research Service (USDA-ARS; Stuttgart, AR) as previously reported and utilized in animal and human studies (Borresen EC, 2016; Goodyear et al. 2015; Sheflin et al. 2016; Sheflin et al. 2015).

Rice was milled using a Yamamoto test whitening machine Rice pal VP-31 T grinder and milling system. This laboratory-based instrument has specifications of high accuracy recovery rate (defined as a maximum of $12 \%$ bran removal from the whole rice grain). Rice samples were milled at room temperature prior to bran preparation. Testing sieve No. 20 was used to separate bran from broken rice and hulls into a clean container. Once separated, milled bran was heat stabilized at $110{ }^{\circ} \mathrm{C}$ for 6 min to prevent rancidity during storage. Rice bran was stored at $-20{ }^{\circ} \mathrm{C}$ until further processing for metabolite analysis. 


\section{Rice Bran Extraction}

Metabolomics analysis was performed by Metabolon Inc. (Durham, NC). Prior to the first step of extraction, several recovery standards (also called quality control standards) were added into the samples for quality control purposes. Quality control standards, that were carefully chosen not to interfere with the measurement of endogenous compounds, were spiked into every analyzed sample to allow instrument performance monitoring and aid chromatographic alignment. The purpose of adding the standards was to assess variability and verify performance of extraction and instrumentation. Values for instrument and process variability met Metabolon's acceptance criteria. Rice bran samples were mixed with $80 \%$ ice-cold methanol under vigorous shaking for 2 min (Glen Mills GenoGrinder 2000) and then were centrifuged to precipitate protein, and free small molecules bound to other macromolecules. The supernatant fraction, i.e., rice bran extract (RBE), was used for further analysis and was divided into four portions: three portions for different mode of analysis by ultraperformance liquid chromatography-tandem mass spectrometry (UPLC-MS/MS) (i.e., one portion for analysis with positive ion mode electrospray ionization, one for negative ion mode electrospray ionization, and one portion for analysis by UPLC-MS/MS polar platform (negative ionization), and one portion for analysis by gas chromatography-mass spectrometry (GC-MS)). Samples were placed briefly on a TurboVap (Zymark) concentration evaporator to remove the organic solvent. For UPLC, the samples were stored overnight under nitrogen before preparation for analysis. For GC, each sample was dried under vacuum overnight before preparation for analysis.

\section{Ultra-Performance Liquid Chromatography-Tandem Mass Spectroscopy (UPLC-MS/MS)}

The UPLC-MS/MS was performed for a non-targeted metabolomics analysis based on a Waters ACQUITY ultra-performance liquid chromatography (UPLC) and a Thermo Scientific Q-Exactive high resolution/accurate mass spectrometer interfaced with a heated electrospray ionization (HESI-II) source and Orbitrap mass analyzer operated at 35,000 mass resolution. The dried RBE was re-suspended in acidic or basic UPLC-compatible solvents. Each sample contained 8 injection quality control standards at fixed concentrations to ensure injection and chromatographic consistency. These standards, in concert with experimental samples, generated a pooled matrix served as technical replicates throughout the data set across all samples and varieties. The acidic solution was analyzed using acidic positive ion optimized conditions, and the basic solution was analyzed using basic negative ion optimized conditions under two identical separate dedicated columns independently (Waters UPLC BEH C18-2.1x100 mm, $1.7 \mu \mathrm{m}$ ). For acidic conditions, RBE was eluted at $350 \mu \mathrm{l} / \mathrm{min}$ from a C18 column using (A) $0.1 \%$ formic acid in water and (B) $0.1 \%$ formic acid in methanol $(0 \% \mathrm{~B}$ to $70 \% \mathrm{~B}$ in $4 \mathrm{~min}, 70-98 \% \mathrm{~B}$ in $0.5 \mathrm{~min}, 98 \% \mathrm{~B}$ for $0.9 \mathrm{~min})$. Likewise, the basic extracts were eluted from $\mathrm{C} 18$ using ammonium bicarbonate instead of formic acid. Another portion of RBE was also analyzed through negative ionization using bicarbonate used (A) $6.5 \mathrm{mM}$ ammonium bicarbonate in water, $\mathrm{pH} 8$, and (B) $6.5 \mathrm{mM}$ ammonium bicarbonate in $95 / 5$ methanol/water (same gradient profile as above) at $350 \mu \mathrm{L} / \mathrm{min}$, followed by elution from a hydrophilic interaction liquid chromatography (HILIC) column (Waters UPLC BEH Amide 2.1x150 mm, $1.7 \mu \mathrm{m}$ ). $10 \mathrm{mM}$ ammonium formate were gradient eluted at $500 \mu \mathrm{L} / \mathrm{min}$ using (A) $10 \mathrm{mM}$ ammonium formate in water and (B) $10 \mathrm{mM}$ ammonium formate in acetonitrile $(5 \%$ B to $50 \%$ $\mathrm{B}$ in $3.5 \mathrm{~min}, 50 \% \mathrm{~B}$ to $95 \% \mathrm{~B}$ in $2 \mathrm{~min}$ and $95 \% \mathrm{~B}$ for $1 \mathrm{~min})$. The MS analysis alternated between MS and datadependent MS2 scans using dynamic exclusion, and the scan range was from $80-1000 \mathrm{~m} / \mathrm{z}$ (Brown et al. 2016).

\section{Gas Chromatography-Mass Spectroscopy (GC-MS)}

The RBEs assigned for GC-MS analysis were dried under vacuum overnight $(18 \mathrm{~h})$. They were further derivatized with bistrimethyl-silyltrifluoroacetamide under dried nitrogen. Derivatized RBEs were separated on a $5 \%$ diphenyl/95\% dimethyl polysiloxane fused silica column (20 m x $0.18 \mathrm{~mm} \mathrm{ID;} 0.18$ um film thickness) with an appropriate carrier gas. Samples were analyzed on a Thermo-Finnigan Trace DSQ $^{\text {ta }}$ fast-scanning singlequadrupole mass spectrometer using electron impact ionization (EI) and operated at unit mass resolving power. The scan range was from $50-750 \mathrm{~m} / \mathrm{z}$ (Brown et al. 2016).

\section{Metabolite Data Extraction and Compound Identification}

Raw instrument data was extracted and then processed through Metabolon in-house developed peak detection and integration software (quantitation is based on area under the curve from MS data). This software uses standard industry approaches for MS peak detection, including using minimum height, signal-to-noise, width and area criteria. These systems are built on a webservice platform utilizing Microsoft's .NET technologies, which run on high-performance application servers and fiber-channel storage arrays in clusters to provide active failover and load-balancing. Compounds were identified by comparison to library entries of purified standards or recurrent unknown entities. Metabolon maintains a library based on authenticated standards that contains the retention time/index (RI), mass to charge ratio $(\mathrm{m} / \mathrm{z})$, and chromatographic data (including MS/MS spectral data) on all molecules present in the library. Biochemical 
identifications were based on three criteria: the experimentally detected signature matching the accurate mass of the authentic standard within $8 \mathrm{ppm}$, i.e. match to the NIST (National Institute of Standards and Technology) library within $+/-0.005$ atomic mass units), retention index match within a defined window (approximately $5 \mathrm{~s}$ ), and the Tandem mass spectrometry (MS/MS) forward and reverse scores between the experimental data and high quality standards. The MS/MS scores are based on a comparison of the ions present in the experimental spectrum to the ions present in the library spectrum. There are more than 3300 commercially purified standard compounds that have been registered in Metabolon Laboratory Information Management System for distribution to both the LC-MS and GC-MS platforms for determination of their analytical characteristics (Evans AM, 2014; Evans et al. 2009).

\section{Statistical Analysis}

A data normalization step was performed to correct variation between instrument inter-day tuning differences. Each compound was corrected in run-day blocks by registering the medians to equal 1.00 and normalizing each data point proportionally. The relative abundance of each metabolite was also normalized by median of the metabolite across the entire dataset (i.e. median-scaled). Median-scaled relative abundance is calculated as: raw abundance of a metabolite/median raw abundance of that metabolite across the entire dataset. Median-scaled relative abundance Z-score was further used as a basis for metabolic pathway network visualization. Z-scores are expressed as standard deviations from the mean and were calculated using the following formula: $z=(x-\mu) / \sigma$ where " $x$ " is median-scaled relative abundance of the metabolite, " $\mu$ " is mean of median-scaled relative abundance for the metabolite across three rice bran varieties, and " $\sigma$ " is the median-scaled relative abundance standard deviation of same metabolite across three varieties. Metabolic pathway and the graphical presentation of metabolite interaction network were composed with Cytoscape version 3.4.0.

\section{Additional files}

Additional file 1: Table S1. Number of metabolites identified in rice bran metabolic pathways. (DOCX $12 \mathrm{~kb}$ )

Additional file 2: Table S2. Rice plant phenotypic characteristics. (DOCX $14 \mathrm{~kb}$ )

\section{Acknowledgements}

This work was supported by a Grand Challenges Explorations in Global Health grant (OPP1015267) from the Bill and Melinda Gates Foundation and a grant from the National Institute of Food and Agriculture (NIFA) and United States Department of Agriculture (USDA) (004228-00002).

\section{Authors' Contributions}

EPR \& IZ conceived and designed the study. IZ performed metabolomics analysis. IZ, DGB, NJN \& EPR interpreted the results and wrote the manuscript. All authors made editorial comments, read and approved the final version of the article.

\section{Competing Interests}

The authors declare that they have no competing interests.

\section{Publisher's Note}

Springer Nature remains neutral with regard to jurisdictional claims in published maps and institutional affiliations.

\section{Author details}

${ }^{1}$ Department of Environmental \& Radiological Health Sciences, College of Veterinary Medicine and Biological Sciences, Colorado State University, 1680 Campus Delivery, Fort Collins, CO 80523, USA. ${ }^{2}$ Institute of Human Nutrition and Food, College of Human Ecology, University of the Philippines Los Baños, Los Baños 4031, Laguna, Philippines.

Received: 15 December 2016 Accepted: 21 April 2017

Published online: 02 June 2017

\section{References}

Abdulmalik O, Ghatge MS, Musayev FN, Parikh A, Chen Q, Yang J et al (2011) Crystallographic analysis of human hemoglobin elucidates the structural basis of the potent and dual antisickling activity of pyridyl derivatives of vanillin. Acta Crystallogr D Biol Crystallogr 67(Pt 11):920-928. doi:10.1107/ s0907444911036353

Aisaka K, Hattori Y, Ishihara T, Morita M, Kase Y, Miyata T (1985) The effects of piperidine and its related substances on blood vessels. Jpn J Pharmacol 37(4):345-353

Andreas NJ, Hyde MJ, Gomez-Romero M, Lopez-Gonzalvez MA, Villasenor A, Wijeyesekera A et al (2015). Multiplatform characterization of dynamic changes in breast milk during lactation. Electrophoresis. doi:10.1002/elps.201500011.

Anraku M, Tsurusaki Y, Watanabe H, Maruyama T, Kragh-Hansen U, Otagiri M (2004) Stabilizing mechanisms in commercial albumin preparations: octanoate and N-acetyl-L-tryptophanate protect human serum albumin against heat and oxidative stress. Biochim Biophys Acta 1702(1):9-17. doi:10.1016/..bbapap.2004.07.002

Antonelli T, Carla V, Lambertini L, Moroni F, Bianchi C (1984) Pyroglutamic acid administration modifies the electrocorticogram and increases the release of acetylcholine and GABA from the guinea-pig cerebral cortex. Pharmacol Res Commun 16(2):189-197

Arbona V, Iglesias DJ, Gomez-Cadenas A (2015) Non-targeted metabolite profiling of citrus juices as a tool for variety discrimination and metabolite flow analysis. BMC Plant Biol 15:38. doi:10.1186/s12870-015-0430-8

Aruoma Ol, Coles LS, Landes B, Repine JE (2012) Functional benefits of ergothioneine and fruit- and vegetable-derived nutraceuticals: overview of the supplemental issue contents. Prev Med 54(Suppl):S4-8. doi:10.1016/ j.ypmed.2012.04.001

Balasubramanian S, Zhu L, Eckert RL (2006) Apigenin inhibition of involucrin gene expression is associated with a specific reduction in phosphorylation of protein kinase Cdelta Tyr311. J Biol Chem 281(47):36162-36172. doi:10.1074/ jbc.M605368200

Barreca D, Lagana G, Leuzzi U, Smeriglio A, Trombetta D, Bellocco E (2016) Evaluation of the nutraceutical, antioxidant and cytoprotective properties of ripe pistachio (Pistacia vera L., variety Bronte) hulls. Food Chem 196:493-502. doi:10.1016/j.foodchem.2015.09.077

Baslow MH (1998) Function of the N-acetyl-L-histidine system in the vertebrate eye. Evidence in support of a role as a molecular water pump. J Mol Neurosci 10(3):193-208. doi:10.1007/bf02761774

Baslow MH, Guilfoyle DN (2015) N-acetyl-L-histidine, a Prominent Biomolecule in Brain and Eye of Poikilothermic Vertebrates. Biomolecules 5(2):635-646. doi:10.3390/biom5020635

Batta AK, Xu G, Honda A, Miyazaki T, Salen G (2006) Stigmasterol reduces plasma cholesterol levels and inhibits hepatic synthesis and intestinal absorption in the rat. Metabolism 55(3):292-299. doi:10.1016/j.metabol.2005.08.024

Beloborodova N, Bairamov I, Olenin A, Shubina V, Teplova V, Fedotcheva N (2012) Effect of phenolic acids of microbial origin on production of reactive 
oxygen species in mitochondria and neutrophils. J Biomed Sci 19:89. doi:10.1186/1423-0127-19-89

Borresen BC, Jenkins-Puccetti N, Schmitz K, Brown DG, Pollack A, Fairbanks A, ... Ryan EP (2017) A Pilot Randomized Controlled Clinical Trial to Assess Tolerance and Efficacy of Navy Bean and Rice Bran Supplementation for Lowering Cholesterol in Children. Glob Pediatr Health, 4, 2333794X17694231. doi: $10.1177 / 2333794 \times 17694231$

Borresen EC, Brown DG, Harbison G, Taylor L, Fairbanks A, O'Malia J et al (2016) A randomized controlled trial to increase navy bean or rice bran consumption in colorectal cancer survivors. Nutr Cancer, 1-15. doi: 10.1080/01635581.2016. 1224370

Bosco MC, Rapisarda A, Massazza S, Melillo G, Young H, Varesio L (2000) The tryptophan catabolite picolinic acid selectively induces the chemokines macrophage inflammatory protein-1 alpha and -1 beta in macrophages. J Immunol 164(6):3283-3291

Brigelius-Flohe R, Traber MG (1999) Vitamin E: function and metabolism. FASEB J 13(10):1145-1155

Brown DG, Rao S, Weir TL, O'Malia J, Bazan M, Brown RJ, Ryan EP (2016) Metabolomics and metabolic pathway networks from human colorectal cancers, adjacent mucosa, and stool. Cancer Metab 4:11. doi:10.1186/s40170-016-0151-y

Capozzi F, Bordoni A (2013) Foodomics: a new comprehensive approach to food and nutrition. Genes Nutr 8(1):1-4. doi:10.1007/s12263-012-0310-x

Carlin G, Djursäter R, Smedegård G, Gerdin B (1985) Effect of anti-inflammatory drugs on xanthine oxidase and xanthine oxidase induced depolymerization of hyaluronic acid. Agents Actions 16(5):377-384. doi:10.1007/bf01982876

Carlsen MH, Halvorsen BL, Holte K, Bøhn SK, Dragland S, Sampson L et al (2010) The total antioxidant content of more than 3100 foods, beverages, spices, herbs and supplements used worldwide. Nutr J 9:3-3. doi:10.1186/ 1475-2891-9-3

Cerino A, Bestagno M, Colonna M, Fussi F, Astaldi Ricotti GC (1988) Carboxyethyl $\gamma$ - Aminobutyric Acid, a polyamine derivative, improves the recovery of EBV-transformed lymphocytes. Biochem Biophys Res Commun 150(3):931-936. doi:10.1016/0006-291X(88)90718-8

Chapouthier G, Venault P (2001) A pharmacological link between epilepsy and anxiety? Trends Pharmacol Sci 22(10):491-493

Charoonratana T, Songsak T, Sakunpak A, Pathompak P, Charoenchai L (2015) Using liquid chromatography-mass spectrometry based metabolomics to discriminate between cold pressed rice bran oils produced from two different cultivars of Oryza sativa L. ssp. indica in Thailand. Se Pu 33(9):966-973

Chatelain E, Boscoboinik DO, Bartoli GM, Kagan VE, Ge y FK, Packer L, Azzi A (1993) Inhibition of smooth muscle cell proliferation and protein kinase $C$ activity by tocopherols and tocotrienols. Biochim Biophys Acta 1176(1-2):83-89

Chen YL, Huang ST, Sun FM, Chiang YL, Chiang CJ, Tsai CM, Weng CJ (2011) Transformation of cinnamic acid from trans- to cis-form raises a notable bactericidal and synergistic activity against multiple-drug resistant Mycobacterium tuberculosis. Eur J Pharm Sci 43(3):188-194. doi:10.1016/ j.ejps.2011.04.012

Chen AC, Martin AJ, Choy B, Fernandez-Penas P, Dalziell RA, McKenzie CA et al (2015) A Phase 3 Randomized Trial of Nicotinamide for Skin-Cancer Chemoprevention. N Engl J Med 373(17):1618-1626. doi:10.1056/ NEJMoa1506197

Cheng HH, Huang HY, Chen YY, Huang CL, Chang CJ, Chen HL, Lai MH (2010) Ameliorative effects of stabilized rice bran on type 2 diabetes patients. Ann Nutr Metab 56(1):45-51. doi:10.1159/000265850

Cherng YG, Tsai CC, Chung HH, Lai YW, Kuo SC, Cheng JT (2013) Antihyperglycemic action of sinapic acid in diabetic rats. J Agric Food Chem 61(49):12053-12059. doi:10.1021/jf403092b

Choi DY, Lee JY, Kim MR, Woo ER, Kim YG, Kang KW (2005) Chrysoeriol potently inhibits the induction of nitric oxide synthase by blocking AP-1 activation. J Biomed Sci 12(6):949-959. doi:10.1007/s11373-005-9028-8

Christophersen, O. A. (2012). Radiation protection following nuclear power accidents: a survey of putative mechanisms involved in the radioprotective actions of taurine during and after radiation exposure. 2012, 23. doi:10.3402/ mehd.v23i0.14787.

Chung MJ, Lee S, Park YI, Lee J, Kwon KH (2016) Neuroprotective effects of phytosterols and flavonoids from Cirsium setidens and Aster scaber in human brain neuroblastoma SK-N-SH cells. Life Sci 148:173-182. doi:10.1016/ j.lfs. 2016.02 .035

Cikman O, Soylemez O, Ozkan OF, Kiraz HA, Sayar I, Ademoglu S et al (2015) Antioxidant Activity of Syringic Acid Prevents Oxidative Stress in I-arginine-
Induced Acute Pancreatitis: An Experimental Study on Rats. Int Surg 100(5):891-896. doi:10.9738/intsurg-d-14-00170.1

Clarke NE, Mosher RE (1953) Phenolic compounds in the treatment of rheumatic fever. II. The metabolism of gentisic acid and the ethanolamide of gentisic acid. Circulation 7(3):337-344

Conlon MA, Bird AR (2015) The Impact of Diet and Lifestyle on Gut Microbiota and Human Health. Nutrients 7(1):17-44. doi:10.3390/nu7010017

Cowan MM (1999) Plant products as antimicrobial agents. Clin Microbiol Rev 12(4):564-582

Craig SA (2004) Betaine in human nutrition. Am J Clin Nutr 80(3):539-549

da Silva MA, Sanches C, Amante ER (2006) Prevention of hydrolytic rancidity in rice bran. J Food Eng 75(4):487-491. doi:10.1016/j.jfoodeng.2005.03.066

Da-Costa-Rocha, I., Bonnlaender, B., Sievers, H., Pischel, I., \& Heinrich, M. (2014). Hibiscus sabdariffa L. - A phytochemical and pharmacological review. Food Chem, 165, 424-443. doi:http://dx.doi.org/10.1016/j.foodchem.2014.05.002.

Dallagnol AM, Catalan CA, Mercado MI, Font de Valdez G, Rollan GC (2011) Effect of biosynthetic intermediates and citrate on the phenyllactic and hydroxyphenyllactic acids production by Lactobacillus plantarum CRL 778 . J Appl Microbiol 111(6):1447-1455. doi:10.1111/j.1365-2672.2011.05159.x

de Munter JS, Hu FB, Spiegelman D, Franz M, van Dam RM (2007) Whole grain, bran, and germ intake and risk of type 2 diabetes: a prospective cohort study and systematic review. PLoS Med 4(8):e261. doi:10.1371/journal. pmed.0040261

De A, Singh MF, Singh V, Ram V, Bisht S (2016) Treatment effect of I-Norvaline on the sexual performance of male rats with streptozotocin induced diabetes. Eur J Pharmacol 771:247-254. doi:10.1016/j.ejphar.2015.12.008

De-Miguel FF, Trueta C (2005) Synaptic and extrasynaptic secretion of serotonin. Cell Mol Neurobiol 25(2):297-312

Dhananjaya BL, Nataraju A, Rajesh R, Raghavendra Gowda CD, Sharath BK, Vishwanath BS, D'Souza CJ (2006) Anticoagulant effect of Naja naja venom 5 'nucleotidase: demonstration through the use of novel specific inhibitor, vanillic acid. Toxicon 48(4):411-421. doi:10.1016/j.toxicon.2006.06.017

Dieuleveux V, Lemarinier S, Gueguen M (1998) Antimicrobial spectrum and target site of D-3-phenyllactic acid. Int J Food Microbiol 40(3):177-183

DrugBank. http://www.drugbank.ca/drugs/DB00765.

Duggal JK, Singh M, Attri N, Singh PP, Ahmed N, Pahwa S et al (2010) Effect of niacin therapy on cardiovascular outcomes in patients with coronary artery disease. J Cardiovasc Pharmacol Ther 15(2):158-166. doi:10.1177/1074248410361337

Egawa M, Nomura J, Iwaki H (2010) The evaluation of the amount of cis- and trans-urocanic acid in the stratum corneum by Raman spectroscopy. Photochem Photobiol Sci 9(5):730-733. doi:10.1039/b9pp00143c

El Idrissi A, Messing J, Scalia J, Trenkner E (2003) Prevention of epileptic seizures by taurine. Adv Exp Med Biol 526:515-525

Evans AM, B. B., Liu Q, Mitchell MW, Robinson RJ, Dai H, Stewart SJ, DeHaven CD and Miller LAD. (2014). High Resolution Mass Spectrometry Improves Data Quantity and Quality as Compared to Unit Mass Resolution Mass Spectrometry in High- Throughput Profiling Metabolomics. Metabolomics, 4(2). doi:http://dx.doi.org/10.4172/2153-0769.1000132

Evans AM, DeHaven CD, Barrett T, Mitchell M, Milgram E (2009) Integrated, nontargeted ultrahigh performance liquid chromatography/electrospray ionization tandem mass spectrometry platform for the identification and relative quantification of the small-molecule complement of biological systems. Anal Chem 81(16):6656-6667. doi:10.1021/ac901536h

Fairfield KM, Fletcher RH (2002) Vitamins for chronic disease prevention in adults: Scientific review. JAMA 287(23):3116-3126. doi:10.1001/jama.287.23.3116

Fay MJ, Verlangieri AJ (1991) Stimulatory action of calcium L-threonate on ascorbic acid uptake by a human T-lymphoma cell line. Life Sci 49(19):1377-1381

Figueroa C, Droppelmann K, Quinones V, Amigo L, Mendoza C, Serrano V et al (2015) Nicotinic acid increases cellular transport of high density lipoprotein cholesterol in patients with hypoalphalipoproteinemia. Rev Med Chil 143(9):1097-1104. doi:10.4067/s0034-98872015000900001

Folkes LK, Wardman P (2001) Oxidative activation of indole-3-acetic acids to cytotoxic species- a potential new role for plant auxins in cancer therapy. Biochem Pharmacol 61(2):129-136

Forster GM, Raina K, Kumar A, Kumar S, Agarwal R, Chen MH et al (2013) Rice varietal differences in bioactive bran components for inhibition of colorectal cancer cell growth. Food Chem 141(2):1545-1552. doi:10.1016/j.foodchem.2013.04.020

Foster AC, Kemp JA (2006) Glutamate- and GABA-based CNS therapeutics. Curr Opin Pharmacol 6(1):7-17. doi:10.1016/j.coph.2005.11.005

Irfan A Ghazi, Iman Zarei, Job O Mapesa, Jessie R Wilburn, Jan E Leach, Sangeeta Rao, et al (2016). Rice Bran Extracts Inhibit Invasion and Intracellular Replication of 
Salmonella typhimurium in Mouse and Porcine Intestinal Epithelial Cells. Med Aromatic Plants (Loa Angel), 5(5), 10. doi:10.4172/2167-0412.1000271.

Ghosh SP, Kulkarni S, Hieber K, Toles R, Romanyukha L, Kao TC et al (2009) Gamma-tocotrienol, a tocol antioxidant as a potent radioprotector. Int J Radiat Biol 85(7):598-606. doi:10.1080/09553000902985128

Goodyear A, Kumar A, Ehrhart EJ, Swanson KS, Grusak MA, Leach JE et al (2015) Dietary rice bran supplementation prevents Salmonella colonization differentially across varieties and by priming intestinal immunity. J Funct Foods 18(Part A):653-664. doi:10.1016/j.jf.2015.08.027

Grant RS, Coggan SE, Smythe GA (2009) The physiological action of picolinic Acid in the human brain. Int J Tryptophan Res 2:71-79

Grioli S, Lomeo C, Quattropani MC, Spignoli G, Villardita C (1990) Pyroglutamic acid improves the age associated memory impairment. Fundam Clin Pharmacol 4(2):169-173

Gurer H, Ozgunes H, Saygin E, Ercal N (2001) Antioxidant effect of taurine against lead-induced oxidative stress. Arch Environ Contam Toxicol 41(4):397-402. doi:10.1007/s002440010265

Guri AJ, Hontecillas R, Si H, Liu D, Bassaganya-Riera J (2007) Dietary abscisic acid ameliorates glucose tolerance and obesity-related inflammation in $\mathrm{db} / \mathrm{db}$ mice fed high-fat diets. Clin Nutr 26(1):107-116. doi:10.1016/j.clnu.2006.07.008

Ham H, Sung J, Lee J (2015) Effect of Rice Bran Unsaponifiables on High-Fat DietInduced Obesity in Mice. J Food Biochem 39(6):673-681. doi:10.1111/jfbc.12170

Hanausek M, Walaszek Z, Slaga TJ (2003) Detoxifying cancer causing agents to prevent cancer. Integr Cancer Ther 2(2):139-144. doi:10.1177/1534735403002002005

Hawley SA, Fullerton MD, Ross FA, Schertzer JD, Chevtzoff C, Walker KJ et al (2012) The ancient drug salicylate directly activates AMP-activated protein kinase. Science 336(6083):918-922. doi:10.1126/science.1215327

Hellmann H, Mooney S (2010) Vitamin B6: a molecule for human health? Molecules 15(1):442-459. doi:10.3390/molecules15010442

Henderson AJ, Ollila CA, Kumar A, Borresen EC, Raina K, Agarwal R, Ryan EP (2012) Chemopreventive properties of dietary rice bran: current status and future prospects. Adv Nutr 3(5):643-653. doi:10.3945/an.112.002303

Herrero M, Simó C, García-Cañas V, Ibáñez E, Cifuentes A (2012) Foodomics: MS-based strategies in modern food science and nutrition. Mass Spectrom Rev 31(1):49-69. doi:10.1002/mas.20335

Hettema JM, An SS, Neale MC, Bukszar J, van den Oord EJ, Kendler KS, Chen X (2006) Association between glutamic acid decarboxylase genes and anxiety disorders, major depression, and neuroticism. Mol Psychiatry 11(8):752-762. doi:10.1038/sj.mp.4001845

Heuberger AL, Lewis MR, Chen MH, Brick MA, Leach JE, Ryan EP (2010) Metabolomic and functional genomic analyses reveal varietal differences in bioactive compounds of cooked rice. PLoS ONE 5(9):e12915. doi:10.1371/journal.pone.0012915

Hinz MC (2003) Serotonin and catecholamine system segment optimization technology. U.S. Patent Application No. 10/394,597, https://www.google. com/patents/US20030181509

Hinz MC (2009) Administration of dopa precursors with sources of dopa to effectuate optimal catecholamine neurotransmitter outcomes. U.S. Patent Application No. 12/400,291, https:/www.google.com/patents/US20090234012

Hirakawa N, Okauchi R, Miura Y, Yagasaki K (2005) Anti-invasive activity of niacin and trigonelline against cancer cells. Biosci Biotechnol Biochem 69(3):653-658

Hu C, Shi J, Quan S, Cui B, Kleessen S, Nikoloski Z et al (2014) Metabolic variation between japonica and indica rice cultivars as revealed by non-targeted metabolomics. Sci Rep 4:5067. doi:10.1038/srep0506, http://www.nature.com/ articles/srep05067\#supplementary-information

Huxtable RJ (1992) Physiological actions of taurine. Physiol Rev 72(1):101

lqbal J, Minhajuddin M, Beg ZH (2003) Suppression of 7,12dimethylbenz[alpha]anthracene-induced carcinogenesis and hypercholesterolaemia in rats by tocotrienol-rich fraction isolated from rice bran oil. Eur J Cancer Prev 12(6):447-453. doi:10.1097/01.cej. $0000102802.33147 .4 b$

lqbal S, Bhanger Ml, Anwar F (2005) Antioxidant properties and components of some commercially available varieties of rice bran in Pakistan. Food Chem 93(2):265-272. doi:10.1016/j.foodchem.2004.09.024

Jiang Q, Elson-Schwab I, Courtemanche C, Ames BN (2000) gamma-tocopherol and its major metabolite, in contrast to alpha-tocopherol, inhibit cyclooxygenase activity in macrophages and epithelial cells. Proc Natl Acad Sci U S A 97(21):11494-11499. doi:10.1073/pnas.200357097

Jo SP, Kim JK, Lim YH (2014) Antihyperlipidemic effects of rhapontin and rhapontigenin from rheum undulatum in rats fed a high-cholesterol diet. Planta Med 80(13):1067-1071. doi:10.1055/s-0034-1382999
Johanningsmeier SD, Harris GK, Klevorn CM (2016) Metabolomic Technologies for Improving the Quality of Food: Practice and Promise. Annu Rev Food Sci Technol 7:413-438. doi:10.1146/annurev-food-022814-015721

Jones DP, Park Y, Ziegler TR (2012) Nutritional metabolomics: progress in addressing complexity in diet and health. Annu Rev Nutr 32:183-202. doi:10.1146/annurev-nutr-072610-145159

Jun HI, Song GS, Yang El, Youn Y, Kim YS (2012) Antioxidant activities and phenolic compounds of pigmented rice bran extracts. J Food Sci 77(7):C759-764. doi:10.1111/j.1750-3841.2012.02763.x

Kadoma Y, Ishihara M, Okada N, Fujisawa S (2006) Free radical interaction between vitamin E (alpha-, beta-, gamma- and delta-tocopherol), ascorbate and flavonoids. Vivo 20(6B):823-827

Kaminska KK, Bertrand HC, Tajima H, Stafford WC, Cheng Q, Chen W et al (2016) Indolin-2-one compounds targeting thioredoxin reductase as potential anticancer drug leads. Oncotarget 7(26):40233-40251. doi:10.18632/ oncotarget.9579

Kanchan Rao Singh MS (2012) Current Perspectives in the Pharmacotherapy of Vertigo. Otorhinolaryngology Clin Int J 4(2):5. doi:10.5005/jp-journals-10003-1091

Kanski J, Aksenova M, Stoyanova A, Butterfield DA (2002) Ferulic acid antioxidant protection against hydroxyl and peroxyl radical oxidation in synaptosomal and neuronal cell culture systems in vitro: structure-activity studies. J Nutr Biochem 13(5):273-281

Kaore SN, Amane HS, Kaore NM (2013) Citrulline: pharmacological perspectives and its role as an emerging biomarker in future. Fundam Clin Pharmacol 27(1):35-50. doi:10.1111/j.1472-8206.2012.01059.x

Khodaeiani E, Fouladi RF, Amirnia M, Saeidi M, Karimi ER (2013) Topical 4\% nicotinamide vs. $1 \%$ clindamycin in moderate inflammatory acne vulgaris. Int J Dermatol 52(8):999-1004. doi:10.1111/ijd.12002

Kim JK, Park S-Y, Lim S-H, Yeo Y, Cho HS, Ha S-H (2013a) Comparative metabolic profiling of pigmented rice (Oryza sativa L.) cultivars reveals primary metabolites are correlated with secondary metabolites. J Cereal Sci 57(1):14-20. doi:10.1016/j.jcs.2012.09.012

Kim N, Kim JK, Hwang D, Lim YH (2013b) The possible mechanism of rhapontigenin influencing antifungal activity on Candida albicans. Med Mycol 51(1):45-52. doi:10.3109/13693786.2012.689021

Kim SP, Park SO, Lee SJ, Nam SH, Friedman M (2014) A Polysaccharide isolated from the liquid culture of Lentinus edodes (Shiitake) mushroom mycelia containing black rice bran protects mice against salmonellosis through upregulation of the Th1 immune reaction. J Agric Food Chem 62(11):2384-2391. doi:10.1021/j405223a

Kleinsorge H, Pohl W (1953) Gentisic acid in therapy of rheumatic polyarthritis. Med Klin 48(29):1038-1040

Kondo S, Teongtip R, Srichana D, Itharat A (2011) Antimicrobial activity of rice bran extracts for diarrheal disease. J Med Assoc Thai 94(Suppl 7):S117-121

Kontush A, Finckh B, Karten B, Kohlschutter A, Beisiegel U (1996) Antioxidant and prooxidant activity of alpha-tocopherol in human plasma and low density lipoprotein. J Lipid Res 37(7):1436-1448

Kosova M, Hradkova I, Matlova V, Kadlec D, Smidrkal J, Filip V (2015) Antimicrobial effect of 4-hydroxybenzoic acid ester with glycerol. J Clin Pharm Ther 40(4):436-440. doi:10.1111/jcpt.12285

Kotani M, Matsumoto M, Fujita A, Higa S, Wang W, Suemura M et al (2000) Persimmon leaf extract and astragalin inhibit development of dermatitis and IgE elevation in NC/Nga mice. J Allergy Clin Immunol 106(1, Part 1):159-166. doi:10.1067/mai.2000.107194

Krajmalnik-Brown R, Ilhan Z-E, Kang D-W, DiBaise JK (2012) Effects of Gut Microbes on Nutrient Absorption and Energy Regulation. Nutr Clin Pract 27(2):201-214. doi:10.1177/0884533611436116

Kumar A, Henderson A, Forster GM, Goodyear AW, Weir TL, Leach JE et al (2012) Dietary rice bran promotes resistance to Salmonella enterica serovar Typhimurium colonization in mice. BMC Microbiol 12:71. doi:10.1186/ 1471-2180-12-71

Kuriyan R, Gopinath N, Vaz M, Kurpad AV (2005) Use of rice bran oil in patients with hyperlipidaemia. Natl Med J India 18(6):292-296

Kwack MH, Ahn JS, Kim MK, Kim JC, Sung YK (2010) Preventable effect of L-threonate, an ascorbate metabolite, on androgen-driven balding via repression of dihydrotestosterone-induced dickkopf-1 expression in human hair dermal papilla cells. BMB Rep 43(10):688-692. doi:10.5483/ BMBRep.2010.43.10.688

Lampe JW, Li SS, Potter JD, King IB (2002) Serum beta-glucuronidase activity is inversely associated with plant-food intakes in humans. J Nutr 132(6):1341-1344 
Larsson SC, Orsini N, Wolk A (2010) Vitamin B6 and risk of colorectal cancer: a meta-analysis of prospective studies. JAMA 303(11):1077-1083. doi:10.1001/ jama.2010.263

Lavermicocca P, Valerio F, Evidente A, Lazzaroni S, Corsetti A, Gobbetti M (2000) Purification and characterization of novel antifungal compounds from the sourdough Lactobacillus plantarum strain 21B. Appl Environ Microbiol 66(9):4084-4090

Lei S, Ramesh A, Twitchell E, Wen K, Bui T, Weiss M et al (2016) High Protective Efficacy of Probiotics and Rice Bran against Human Norovirus Infection and Diarrhea in Gnotobiotic Pigs. Front Microbiol 7:1699. doi:10.3389/ fmicb.2016.01699

Leon R, Wu H, Jin Y, Wei J, Buddhala C, Prentice H, Wu JY (2009) Protective function of taurine in glutamate-induced apoptosis in cultured neurons. J Neurosci Res 87(5):1185-1194. doi:10.1002/jnr.21926

Li XX, Chen XL, Zhang MH, Wang YH, Da WM, Li JY (2005) A randomized controlled and multicenter clinical study of ferrous L-threonate in treatment of iron deficiency anemia. Zhonghua Nei Ke Za Zhi 44(11):844-847

Li W, Fotinos A, Wu Q, Chen Y, Zhu Y, Baranov S et al (2015) N-acetyl-Ltryptophan delays disease onset and extends survival in an amyotrophic lateral sclerosis transgenic mouse model. Neurobiol Dis 80:93-103. doi:10.1016/j.nbd.2015.05.002

Liao JC, Lee KT, You BJ, Lee CL, Chang WT, Wu YC, Lee HZ (2015) Raf/ERK/Nrf2 signaling pathway and MMP-7 expression involvement in the trigonellinemediated inhibition of hepatocarcinoma cell migration. Food Nutr Res 59:29884. doi:10.3402/fnr.v59.29884

Liliana Hernández Vázquez, J. P. a. A. N.-O. (2012). The Pentacyclic Triterpenes a, $\beta$-amyrins: A Review of Sources and Biological Activities Phytochemicals A Global Perspect Role Nutr Health, 17. doi:10.5772/27253.

Lin Y, Shi R, Wang X, Shen H-M (2008) Luteolin, a flavonoid with potentials for cancer prevention and therapy. Curr Cancer Drug Targets 8(7):634-646

Lü J-M, Lin PH, Yao Q, Chen C (2010) Chemical and molecular mechanisms of antioxidants: experimental approaches and model systems. J Cell Mol Med 14(4):840-860. doi:10.1111/j.1582-4934.2009.00897.x

Luca Narduzzi JS, Mattivi F (2015) Comparing Wild American Grapes with Vitis vinifera: A Metabolomics Study of Grape Composition. J Agric Food Chem 63(30):12. doi:10.1021/acs.jafc.5b01999

Makni M, Chtourou Y, Fetoui H, el Garoui M, Boudawara T, Zeghal N (2011) Evaluation of the antioxidant, anti-inflammatory and hepatoprotective properties of vanillin in carbon tetrachloride-treated rats. Eur J Pharmacol 668(1-2):133-139. doi:10.1016/j.ejphar.2011.07.001

Makni M, Chtourou Y, Barkallah M, Fetoui H (2012) Protective effect of vanillin against carbon tetrachloride (CCl(4))-induced oxidative brain injury in rats. Toxicol Ind Health 28(7):655-662. doi:10.1177/0748233711420472

Mero AA, Ojala T, Hulmi JJ, Puurtinen R, Karila TA, Seppala T (2010) Effects of alfa-hydroxy-isocaproic acid on body composition, DOMS and performance in athletes. J Int Soc Sports Nutr 7:1. doi:10.1186/1550-2783-7-1

Ming X-F, Rajapakse AG, Carvas JM, Ruffieux J, Yang Z (2009) Inhibition of S6K1 accounts partially for the anti-inflammatory effects of the arginase inhibitor L-norvaline. BMC Cardiovasc Disord 9:12-12. doi:10.1186/1471-2261-9-12

Mishra B, Priyadarsini KI, Kumar MS, Unnikrishnan MK, Mohan H (2003) Effect of O-glycosilation on the antioxidant activity and free radical reactions of a plant flavonoid, chrysoeriol. Bioorg Med Chem 11(13):2677-2685

Mnafgui K, Derbali A, Sayadi S, Gharsallah N, Elfeki A, Allouche N (2015) Anti-obesity and cardioprotective effects of cinnamic acid in high fat diet- induced obese rats. J Food Sci Technol 52(7):4369-4377. doi:10.1007/s13197-014-1488-2

Moco S, Bino RJ, Vorst O, Verhoeven HA, de Groot J, van Beek TA et al (2006) A liquid chromatography-mass spectrometry-based metabolome database for tomato. Plant Physiol 141(4):1205-1218. doi:10.1104/pp.106.078428

Morales-González JA (2013) Oxidative stress and chronic degenerative diseases-a role for antioxidants. Rijeka: Croatia InTech, 500. https://www.intechopen. com/books/oxidative-stress-and-chronic-degenerative-diseases-a-role-forantioxidants

Muthayya S, Sugimoto JD, Montgomery S, Maberly GF (2014) An overview of global rice production, supply, trade, and consumption. Ann N Y Acad Sc 1324:7-14. doi:10.1111/nyas.12540

Muthukumaran J, Srinivasan S, Venkatesan RS, Ramachandran V, Muruganathan U (2013) Syringic acid, a novel natural phenolic acid, normalizes hyperglycemia with special reference to glycoprotein components in experimental diabetic rats. J Acute Dis 2(4):304-309. doi:10.1016/\$2221-6189(13)60149-3
Nascimento GGF, Locatelli J, Freitas PC, Silva GL (2000) Antibacterial activity of plant extracts and phytochemicals on antibiotic-resistant bacteria. Braz J Microbiol 31:247-256

Nealon NJ, Worcester CR, \& Ryan EP (2017) Lactobacillus paracasei metabolism of rice bran reveals metabolome associated with salmonella Typhimurium growth reduction. J Appl Microbiol. doi: 10.1111/jam.13459

Nimse SB, Pal D (2015) Free radicals, natural antioxidants, and their reaction mechanisms. RSC Adv 5(35):27986-28006. doi:10.1039/C4RA13315C

Niren NM (2006) Pharmacologic doses of nicotinamide in the treatment of inflammatory skin conditions: a review. Cutis 77(1 Suppl):11-16

Olthof MR, Hollman PC, Katan MB (2001) Chlorogenic acid and caffeic acid are absorbed in humans. J Nutr 131(1):66-71

Oxenkrug GF (1999) Antidepressive and antihypertensive effects of MAO-A inhibition: role of $\mathrm{N}$-acetylserotonin. A review. Neurobiology (Bp) 7(2):213-224

Oxenkrug GF, Sablin SO, Requintina PJ (2007) Effect of methylene blue and related redox dyes on monoamine oxidase activity; rat pineal content of $\mathrm{N}$-acetylserotonin, melatonin, and related indoles; and righting reflex in melatonin-primed frogs. Ann N Y Acad Sci 1122:245-252. doi:10.1196/ annals.1403.017

Pacheco R, Gallart T, Lluis C, Franco R (2007) Role of glutamate on T-cell mediated immunity. J Neuroimmunol 185(1-2):9-19. doi:10.1016/ j.jneuroim.2007.01.003

Panala V, M. V, Boateng J, Field R, Shackelford L, Walker LT (2009) A Comparison of Rice Bran, Corn Oil and Soybean Oil Against Azoxymethane Induced Colon Cancer in a Fisher 344 Rat Model. Int J Cancer Res 5(1):11. doi:10.3923/ijcr.2009.25.35

Panico AM, Cardile V, Garufi F, Puglia C, Bonina F, Ronsisvalle G (2005) Protective effect of Capparis spinosa on chondrocytes. Life Sci 77(20):2479-2488. doi:10.1016/j.lfs.2004.12.051

Parrado J, Miramontes E, Jover M, Márquez JC, AngelesMejias M, CollantesdeTeran L et al (2003) Prevention of brain protein andlipid oxidation elicited by a water-soluble oryzanol enzymaticextract derived from rice bran. Eur J Nutr 42(6):307-314. doi:10.1007/s00394-003-0424-4

Parrado J, Miramontes E, Jover M, Gutierrez JF, Collantes de Terán L, Bautista J (2006) Preparation of a rice bran enzymatic extract with potential use as functional food. Food Chem 98(4):742-748. doi:10.1016/j.foodchem. 2005.07.016

Patel K, Chen Y, Dennehy K, Blau J, Connors S, Mendonca M et al (2006) Acute antihypertensive action of nitroxides in the spontaneously hypertensive rat. Am J Physiol Regul Integr Comp Physiol 290(1):R37-43. doi:10.1152/ ajpregu.00469.2005

Percudani R, Peracchi A (2009) The B6 database: a tool for the description and classification of vitamin B6-dependent enzymatic activities and of the corresponding protein families. BMC Bioinformatics 10(1):273. doi:10.1186/ 1471-2105-10-273

Perianayagam MC, Oxenkrug GF, Jaber BL (2005) Immune-Modulating Effects of Melatonin, N-Acetylserotonin, and N-Acetyldopamine. Ann N Y Acad Sci 1053(1):386-393. doi:10.1111/j.1749-6632.2005.tb00046.x

Pero RW, Lund H, Leanderson T (2009) Antioxidant metabolism induced by quinic acid. Increased urinary excretion of tryptophan and nicotinamide. Phytother Res 23(3):335-346. doi:10.1002/ptr.2628

Peroutka SJ, Lebovitz RM, Snyder SH (1981) Two distinct central serotonin receptors with different physiological functions. Science 212(4496):827-829

Pietersen HG, Langenberg CJ, Geskes G, Soeters PB, Wagenmakers AJ (1998) Glutamate metabolism of the heart during coronary artery bypass grafting. Clin Nutr 17(2):73-75

Piletz JE, Aricioglu F, Cheng J-T, Fairbanks CA, Gilad VH, Haenisch B et al (2013) Agmatine: clinical applications after 100 years in translation. Drug Discov Today 18(17-18):880-893. doi:10.1016/j.drudis.2013.05.017

Pompella A, Visvikis A, Paolicchi A, De Tata V, Casini AF (2003) The changing faces of glutathione, a cellular protagonist. Biochem Pharmacol 66(8):1499-1503

Przybylski C (2008) Use of acetyl-leucine for preparing a drug for treating balance disorders. U.S. Patent Application No. 11/886,419. https:/www.google.com/ patents/US20080108702

Qian Q, Guo L, Smith SM, \& Li J. (2016). Breeding high-yield superior quality hybrid super rice by rational design. Natl Sci Rev. doi:10.1093/nsr/nww006.

Qureshi AA, Bradlow BA, Salser WA, Brace LD (1997) Novel tocotrienols of rice bran modulate cardiovascular disease risk parameters of hypercholesterolemic humans. J Nutr Biochem 8(5):290-298. doi:10.1016/ S0955-2863(97)89667-2 
Qureshi AA, Sami SA, Khan FA (2002) Effects of stabilized rice bran, its soluble and fiber fractions on blood glucose levels and serum lipid parameters in humans with diabetes mellitus Types I and II. J Nutr Biochem 13(3):175-187

Raasch W, Schäfer U, Chun J, Dominiak P (2001) Biological significance of agmatine, an endogenous ligand at imidazoline binding sites. Br J Pharmacol 133(6):755-780. doi:10.1038/sj.bjp.0704153

Rajendra Prasad N, Karthikeyan A, Karthikeyan S, Venkata Reddy B (2011) Inhibitory effect of caffeic acid on cancer cell proliferation by oxidative mechanism in human HT-1080 fibrosarcoma cell line. Mol Cell Biochem 349(1):11-19. doi:10.1007/s11010-010-0655-7

Ramezanzadeh FM, Rao RM, Windhauser M, Prinyawiwatkul W, Marshall WE (1999a) Prevention of oxidative rancidity in rice bran during storage. J Agric Food Chem 47(8):2997-3000

Ramezanzadeh FM, Rao RM, Windhauser M, Prinyawiwatkul W, Tulley R, Marshall WE (1999b) Prevention of hydrolytic rancidity in rice bran during storage. J Agric Food Chem 47(8):3050-3052

Reiter RJ, Tan DX, Cabrera J, D'Arpa D (1999) Melatonin and tryptophan derivatives as free radical scavengers and antioxidants. Adv Exp Med Biol 467:379-387

Sakko M, Tjaderhane L, Sorsa T, Hietala P, Jarvinen A, Bowyer P, Rautemaa R (2012) 2-Hydroxyisocaproic acid (HICA): a new potential topical antibacterial agent. Int J Antimicrob Agents 39(6):539-540. doi:10.1016/j.ijantimicag.2012.02.006

Sakko M, Moore C, Novak-Frazer L, Rautemaa V, Sorsa T, Hietala P et al (2014) 2-hydroxyisocaproic acid is fungicidal for Candida and Aspergillus species. Mycoses 57(4):214-221. doi:10.1111/myc.12145

Saunders RM (1990) The properties of rice bran as a foodstuff. Cereal Foods World 35(7):5

Scriabine A, Ludden CT, Sweet CS, Porter CC, Ulm EH, Stone CA et al (1978) Antihypertensive activity of metyrosine in spontaneously hypertensive rats and its enhancement by carbidopa. Clin Sci Mol Med Suppl, 4:255s-257s

SELFNutritionDada. Rice bran, crude Nutritional Facts \& Calories. http:// nutritiondata.self.com/facts/cereal-grains-and-pasta/5725/2

Serbinova E, Kagan V, Han D, Packer L (1991) Free radical recycling and intramembrane mobility in the antioxidant properties of alpha-tocopherol and alpha-tocotrienol. Free Radic Biol Med 10(5):263-275. doi:10.1016/ 0891-5849(91)90033-Y

Shang YJ, B Y L, M M Z (2015) Details of the Antioxidant Mechanism of Hydroxycinnamic Acids. Czech J Food Sci 33(3):7. doi:10.17221/611/2014-CJFS

Sheflin AM, Borresen EC, Wdowik MJ, Rao S, Brown RJ, Heuberger AL et al (2015) Pilot dietary intervention with heat-stabilized rice bran modulates stool microbiota and metabolites in healthy adults. Nutrients 7(2):1282-1300. doi:10.3390/nu7021282

Sheflin, A. M., Borresen, E. C., Kirkwood, J. S., Boot, C. M., Whitney, A. K., Lu, S., et al. (2016). Dietary supplementation with rice bran or navy bean alters gut bacterial metabolism in colorectal cancer survivors. Mol Nutr Food Res. doi:10.1002/mnfr.201500905

Shi C, Sun Y, Zheng Z, Zhang X, Song K, Jia Z et al (2016) Antimicrobial activity of syringic acid against Cronobacter sakazakii and its effect on cell membrane. Food Chem 197(Pt A):100-106. doi:10.1016/j.foodchem.2015.10.100

Shibata, A., Kawakami, Y., Kimura, T., Miyazawa, T., \& Nakagawa, K. (2016). alpha-Tocopherol Attenuates the Triglyceride- and Cholesterol-Lowering Effects of Rice Bran Tocotrienol in Rats Fed a Western Diet. J Agric Food Chem. doi:10.1021/acs.jafc.6b02228.

Singh A, G. K. U (2015) A review on Carissa carandas - phytochemistry, ethno- pharmacology, and micropropagation as conservation strategy. Asian J Pharm Clin Res 8(3):5

Singh G, Passsari AK, Leo W, Mishra VK, Subbarayan S, Singh BP et al (2016) Evaluation of Phenolic Content Variability along with Antioxidant, Antimicrobial, and Cytotoxic Potential of Selected Traditional Medicinal Plants from India. Front Plant Sci 7:407. doi:10.3389/fpls.2016.00407

Sinha M, Manna P, Sil PC (2008) Taurine protects the antioxidant defense system in the erythrocytes of cadmium treated mice. BMB Rep 41(9):657-663

Song F, Li H, Sun J, Wang S (2013) Protective effects of cinnamic acid and cinnamic aldehyde on isoproterenol-induced acute myocardial ischemia in rats. J Ethnopharmacol 150(1):125-130. doi:10.1016/j.jep.2013.08.019

Srivastava J, Chandra H, Nautiyal AR, Kalra SJS (2014) Antimicrobial resistance (AMR) and plant-derived antimicrobials (PDA(m)s) as an alternative drug line to control infections. 3 Biotech 4(5):451-460. doi:10.1007/s13205-013-0180-y

Sugino T, Shirai T, Kajimoto Y, Kajimoto O (2008) L-ornithine supplementation attenuates physical fatigue in healthy volunteers by modulating lipid and amino acid metabolism. Nutr Res 28(11):738-743. doi:10.1016/j.nutres.2008.08.008
Surjana D, Halliday GM, Martin AJ, Moloney FJ, Damian DL (2012) Oral Nicotinamide Reduces Actinic Keratoses in Phase II Double-Blinded Randomized Controlled Trials. J Investig Dermatol 132(5):1497-1500. doi:10.1038/jid.2011.459

Swargiary A, B. R (2015) in vitro anthelmintic efficacy of alpinia nigra and its bioactive compound, astragalin against fasciolopsis buski. Int J Pharm Pharm Sci 7(10):6

Touitou Y (2001) Human aging and melatonin. Clinical relevance. Exp Gerontol 36(7):1083-1100

Tsuboyama-Kasaoka N, Shozawa C, Sano K, Kamei Y, Kasaoka S, Hosokawa Y, Ezaki O (2006) Taurine (2-aminoethanesulfonic acid) deficiency creates a vicious circle promoting obesity. Endocrinology 147(7):3276-3284. doi:10.1210/en.2005-1007

Turunc Bayrakdar E, Uyanikgil Y, Kanit L, Koylu E, Yalcin A (2014) Nicotinamide treatment reduces the levels of oxidative stress, apoptosis, and PARP-1 activity in $A \beta(1-42)$-induced rat model of Alzheimer's disease. Free Radic Res 48(2):146-158. doi:10.3109/10715762.2013.857018

US Department of Agriculture, Agricultural research service, Nutrient data Laboratory. USDA National Nutrient Database for Standard Reference, Release 28. Version Current: September 2015, slightly revised May 2016. Internet: / nea/bhnrc/ndl

Upadhyay R, Mohan Rao LJ (2013) An Outlook on Chlorogenic Acids-Occurrence, Chemistry, Technology, and Biological Activities. Crit Rev Food Sci Nutr 53(9):968-984. doi:10.1080/10408398.2011.576319

Valerio F, Lavermicocca P, Pascale M, Visconti A (2004) Production of phenyllactic acid by lactic acid bacteria: an approach to the selection of strains contributing to food quality and preservation. FEMS Microbiol Lett 233(2):289-295. doi:10.1016/j.femsle.2004.02.020

Vargo MA, Voss OH, Poustka F, Cardounel AJ, Grotewold E, Doseff Al (2006) Apigenin-induced-apoptosis is mediated by the activation of PKCdelta and caspases in leukemia cells. Biochem Pharmacol 72(6):681-692. doi:10.1016/j.bcp.2006.06.010

Verschoyle RD, Greaves P, Cai H, Edwards RE, Steward WP, Gescher AJ (2007) Evaluation of the cancer chemopreventive efficacy of rice bran in genetic mouse models of breast, prostate and intestinal carcinogenesis. Br J Cancer 96(2):248-254. doi:10.1038/sj.bjc.6603539

Wang M, Hettiarachchy NS, Qi M, Burks W, Siebenmorgen T (1999) Preparation and functional properties of rice bran protein isolate. J Agric Food Chem 47(2):411-416

Wang J, Shimada M, Kato Y, Kusada M, Nagaoka S (2015) Cholesterollowering effect of rice bran protein containing bile acid-binding proteins. Biosci Biotechnol Biochem 79(3):456-461. doi:10.1080/09168451. 2014.978260

Wishart DS (2008) Metabolomics: applications to food science and nutrition research. Trends Food Sci Technol 19(9):482-493. doi:10.1016/j.tifs.2008.03.003

Wu J, Domellof M, Zivkovic AM, Larsson G, Ohman A, Nording ML (2016) NMR-based metabolite profiling of human milk: A pilot study of methods for investigating compositional changes during lactation. Biochem Biophys Res Commun 469(3):626-632. doi:10.1016/j.bbrc.2015.11.114

Yanagita T, Han S-Y, Hu Y, Nagao K, Kitajima H, Murakami S (2008) Taurine reduces the secretion of apolipoprotein B100 and lipids in HepG2 cells. Lipids Health Dis 7(1):38. doi:10.1186/1476-511X-7-38

Yang X, Wen K, Tin C, Li G, Wang H, Kocher J et al (2014) Dietary rice bran protects against rotavirus diarrhea and promotes Th1-type immune responses to human rotavirus vaccine in gnotobiotic pigs. Clin Vaccine Immunol 21(10):1396-1403. doi:10.1128/cvi.00210-14

Yang X, Twitchell E, Li G, Wen K, Weiss M, Kocher J et al (2015) High protective efficacy of rice bran against human rotavirus diarrhea via enhancing probiotic growth, gut barrier function, and innate immunity. Sci Rep 5:15004. doi:10.1038/srep15004

Yarlagadda A, Clayton AH (2007) Blood Brain Barrier: The Role of Pyridoxine. Psychiatry (Edgmont) 4(8):58-60

Yemis GP, Pagotto F, Bach S, Delaquis P (2011) Effect of vanillin, ethyl vanillin, and vanillic acid on the growth and heat resistance of Cronobacter species. J Food Prot 74(12):2062-2069. doi:10.4315/0362-028x.jfp-11-230

Yun KJ, Koh DJ, Kim SH, Park SJ, Ryu JH, Kim DG et al (2008) Anti-inflammatory effects of sinapic acid through the suppression of inducible nitric oxide synthase, cyclooxygase-2, and proinflammatory cytokines expressions via nuclear factor-kappaB inactivation. J Agric Food Chem 56(21):10265-10272. doi:10.1021/jf802095g 
Zema MJ (2000) Gemfibrozil, nicotinic acid and combination therapy in patients with isolated hypoalphalipoproteinemia: a randomized, open-label, crossover study. J Am Coll Cardiol 35(3):640-646. doi:10.1016/S0735-1097(99)00585-9

Zhang R, Kang KA, Piao MJ, Lee KH, Jang HS, Park MJ et al (2007) Rhapontigenin from Rheum undulatum protects against oxidative-stress-induced cell damage through antioxidant activity. J Toxicol Environ Health A 70(13):1155-1166. doi:10.1080/15287390701252766

Zhihong Gao JS, Sun H, Zhong W, Zhuang W, Zhang Z (2012) Evaluation of different kinds of organic acids and their antibacterial activity in Japanese Apricot fruits. Afr J Agric Res 7(35):8. doi:10.5897/AJAR12.1347

Zhu M, Du J, Liu AD, Holmberg L, Chen SY, Bu D et al (2015) L-cystathionine inhibits oxidized low density lipoprotein-induced THP-1-derived macrophage inflammatory cytokine monocyte chemoattractant protein-1 generation via the NF-kappaB pathway. Sci Rep 5:10453. doi:10.1038/srep10453

Zhu B, Shang B, Li Y, Zhen Y (2016) Inhibition of histone deacetylases by trans-cinnamic acid and its antitumor effect against colon cancer xenografts in athymic mice. Mol Med Rep 13(5):4159-4166. doi:10.3892/mmr.2016.5041

\section{Submit your manuscript to a SpringerOpen ${ }^{\circ}$ journal and benefit from:}

- Convenient online submission

- Rigorous peer review

- Immediate publication on acceptance

- Open access: articles freely available online

- High visibility within the field

- Retaining the copyright to your article

Submit your next manuscript at $\boldsymbol{s p r i n g e r o p e n . c o m ~}$ 